\title{
Evaluation of the Physico-chemical properties of an amorphous magnesium silicate synthesized by an ultrasound-assisted precipitation.
}

\author{
Marie Dietemann ${ }^{\mathrm{a}, *}$, Fabien Baillon ${ }^{\mathrm{a}}$, Fabienne Espitalier ${ }^{\mathrm{a}}$, Rachel Calvet $^{\mathrm{a}}$, \\ Philippe Accart ${ }^{\mathrm{a}}$, Sylvie Del Confetto ${ }^{\mathrm{a}}$, Mike Greenhill-Hooper ${ }^{\mathrm{b}}$ \\ ${ }^{a}$ Université de Toulouse, Mines d'Albi, UMR CNRS 5302, Centre RAPSODEE, Campus \\ Jarlard F-81013 Albi Cedex 09, France \\ ${ }^{b}$ Imerys Talc, 2 Place E. Bouillères, 31036 Toulouse, France
}

\begin{abstract}
Natural talc is a very interesting filler for plastic and rubber materials and paints because it improves their properties by delivering mechanical reinforcement and barrier effects.Good dispersion in a polymer matrix requires fine particles, of nanometric size that are easy to disperse. However, at the moment the main drawback in the use of natural talc is that, with a conventional milling process, nanometric particle sizes are difficult and expensive to obtain. The objective of this study is to develop a process of magnesium silicate synthesis made by precipitation. This step is the first in the manufacturing process of synthetic talc.

This study examines the influence of different process parameters on product properties (the way the reactants are added, the reactants themselves, molalities and ultrasound). The synthesized product is highly agglomerated, whatever process parameters are used, but the use of some specific parameters could result in a reduction in the size of the agglomerates. The addition of reactants by a mixing system with ultrasound during the synthesis could be the best method to synthesize the smallest particles. Moreover initial reactant molalities influence the nucleation rate and thus the agglomeration phenomenon. But initial reactant molalities also have an effect on solid purity. Amorphous silica can co-precipitate with magnesium silicate in some molality ranges.
\end{abstract}

\footnotetext{
*. Corresponding author

Email addresses: Marie.Dietemann@mines-albi.fr (Marie Dietemann), Fabienne.Espitalier@mines-albi.fr (Fabienne Espitalier), Mike.GreenhillHooper@imerys.com (Mike Greenhill-Hooper)
} 
Keywords: magnesium silicate, precipitation, silica, agglomeration, product solubility

\section{Introduction}

Natural talc is an interesting material that can be used as high performance filler in polymers. It improves their properties, giving, for instance,excellent mechanical reinforcement and improved barrier effects [1]. In plastics, talc improves tensile and transverse strength and the modulus of elasticity [2]. In rubbers, talc is interesting because of its lubricating properties [2]. Talc also improves resistance to corrosion of paints. It also changes their flow properties, makes spreading easier and reinforces covering power [3]. However, a homogeneous dispersion of the filler in the polymer matrix is necessary to obtain these different performances. A good dispersion in a polymer matrix requires, in an ideal case, particles to be nano-sized [4]. Moreover, if the solid is agglomerated, its dis-agglomeration needs to be easy in the polymer matrix. This dis-agglomeration should lead to the dispersion of primary particles in the polymer matrix. However, it is difficult to obtain nanometric particles using conventional milling processes. An alternative method to milling is the chemical synthesis of talc. Two steps are required. The first step consists of magnesium silicate precipitation with the production of an amorphous solid. A second step is necessary to convert the amorphous solid into crystalline lamellar nano-sized particles with a talc-like structure. Depending on the industrial application, the filler, magnesium silicate in this study, must be amorphous or crystalline. In order to fill rubber, for example, magnesium silicate should be amorphous. On the other hand, the product must be crystalline to fill paints. Industrial applications of amorphous magnesium silicate are in plastics and rubbers.

The second step of the process of producing synthetic talc has been the subject of several investigations by Lèbre [5]. But, with the exception of the works of Ciesielczyk, Krysztafkiewicz, and Jesionowski [6, 7], Ciesielczyk et al. [1], few investigations have been carried out into precipitation. The works of Ciesielczyk and his colleagues focused on applications of magnesium silicate as an adsorbent of organic compounds, whereas, in this paper, magnesium silicate is studied to assess its use as a load in a polymer matrix. However, they did study the effects of some process parameters and solid treatments on solid properties. These solid properties were the state of crystallinity, particle-size distribution, morphology, nitrogen adsorption

properties, porosity and the ability to absorb different solvents according to 
process parameters and solid treatment. Ciesielczyk showed that the reactant addition mode presents an effect on solid hydrophobicity [7]. Moreover, the magnesium silicate is amorphous in each experiment, indicating that neither the way reactants are added nor the synthesis temperature have an effect on the crystallinity state of the solid [7].

The aim of this work is to study the influence of precipitation parameters on product properties. Synthesized particles-size distributions and agglomeration phenomena are the most important properties that are observed in this study. Some process parameters, such as reactant molalities, temperature and the mixing system used with an ultrasound probe present an influence on the properties of a precipitated product, in particular on particle-size distributions [8]. According to Dodds, Espitalier, Louisnard, Grossier, David, Hassoun, Baillon, Gatumel, and Lyczko [9], the use of ultrasound during the synthesis also influences particle size. It has been shown that $\mathrm{BaSO}_{4}, \mathrm{~K}_{2} \mathrm{SO}_{4}, \mathrm{TiO}_{2}$ and sucrose crystals are smaller when crystallisation or precipitation is made with ultrasound. In this work, the influence of ultrasound on particle-size distributions is studied.

\section{Experimental}

\subsection{Materials}

The amorphous magnesium silicate was synthesized by a precipitation between a sodium metasilicate solution $\left(\mathrm{Na}_{2} \mathrm{SiO}_{3}, 5 \mathrm{H}_{2} \mathrm{O}\right)$ and an acid magnesium chloride solution $\left(\mathrm{MgCl}_{2}, 6 \mathrm{H}_{2} \mathrm{O}\right)$, according to the following equation [4] :

$$
4 \mathrm{Na}_{2} \mathrm{SiO}_{3}, 5 \mathrm{H}_{2} \mathrm{O}+3 \mathrm{MgCl}_{2}, 6 \mathrm{H}_{2} \mathrm{O}+2 \mathrm{HCl}=\mathrm{Si}_{4} \mathrm{Mg}_{3} \mathrm{O}_{11}, \mathrm{nH}_{2} \mathrm{O}+8 \mathrm{NaCl}+(39-\mathrm{n}) \mathrm{H}_{2} \mathrm{O}
$$

The reactants were aqueous solutions of sodium metasilicate (purity $95^{\%}$ ), called reactant 1 , and of magnesium chloride (purity $99 \%$ ), called reactant 2 (supplier Prolabo). The initial molar ratio $\mathrm{Mg} / \mathrm{Si}$ was always 0.75 , corresponding to that of natural talc. Hydrochloric acid $1 \mathrm{M}$ was added to the aqueous solution of magnesium chloride (supplier Prolabo). Demineralized water was used. At the end of the synthesis, a part of the solid was dried at $550^{\circ} \mathrm{C}$ for 18 hours. The solid weight loss gave an estimation of the value of n. 


\subsection{Procedures and Methods}

\subsubsection{Synthesis of magnesium silicate}

Fig. 1 is a flow diagram of magnesium silicate synthesis. The main step of the process is the precipitation operation that enables magnesium silicate to be synthesized. After the synthesis, the suspension needs to be treated by several steps of filtration and washing and the solid obtained needs to be dried and milled. Each step will be explained in the following section.

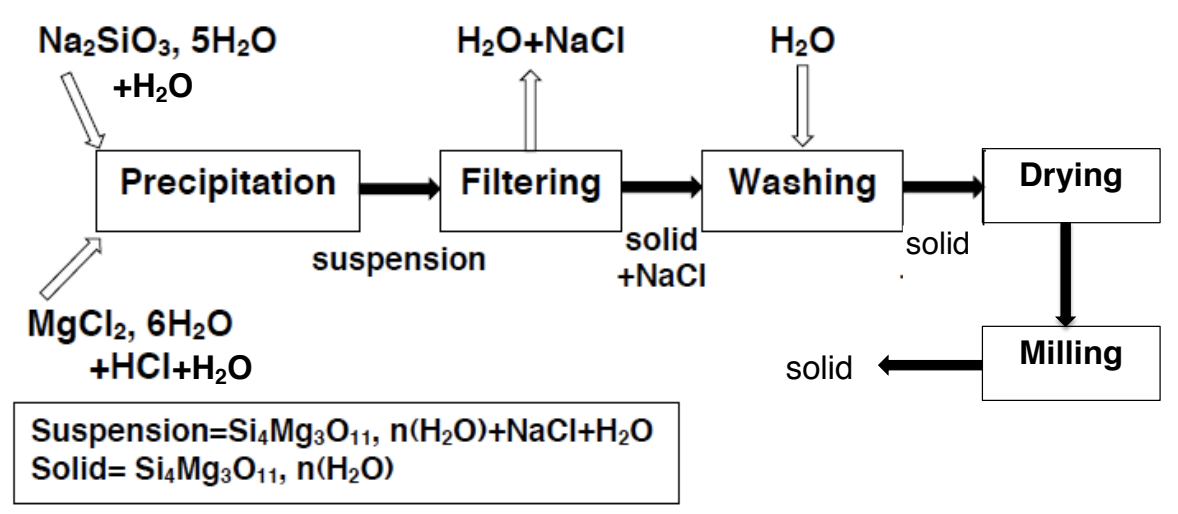

FIGURE 1: Flow diagram of dried magnesium silicate synthesis.

This synthesis was made in a vessel with four baffles, at constant temperature and at a stirring rate of $600 \mathrm{rpm}$. The total volume of the suspension was 1L. The mixing device was a PTFE helix propeller with four squared blades. Its diameter was $4 \mathrm{~cm}$. Three addition modes were tested. The first mode was slow addition, drop by drop, of one reactant into the other (Fig. 2a). The second mode was the fast addition of one reactant into the other. This mode is not depicted in Fig. 2 because the materials are the same as for slow addition. The only difference is that magnesium chloride solution was instantaneously added. In the third mode, the reactants were mixed in a mixing system (Fig. 2b). Peristaltic pumps were used to feed solutions into the mixing system. Rates and speeds of flow were respectively 125.25 g.min ${ }^{-1}$ and $0.30 \mathrm{~m} . \mathrm{s}^{-1}$ for the sodium metasilicate solution and 81.30 g. $\mathrm{min}^{-1}$ and $0.19 \mathrm{~m} . \mathrm{s}^{-1}$ for the magnesium chloride solution. Mixing occurred inside the mixing system at the exit of the pipes coming from the pumps. At the exit of the mixing system, the suspension was poured into 
the vessel which was initially filled with $100 \mathrm{~mL}$ of demineralised water. Ultrasound was used in the mixing system $(\mathrm{f}=20 \mathrm{kHz})$. The ultrasound power dissipation in the solution was measured by the calorimetry method and found to be equal to $34.5 \mathrm{~W}$.

When experiments were conducted at a higher temperature than room temperature $\left(40\right.$ or $\left.50^{\circ} \mathrm{C}\right)$ the reactants were heated with hotplates. The vessel was maintained at 40 or $50^{\circ} \mathrm{C}$ using a constant-temperature bath.

During the synthesis, the $\mathrm{pH}$ and the temperature of the solution were measured. By obtaining the stability of the $\mathrm{pH}$ it was possible to determine the end of the reaction and the state of equilibrium of the suspension.

The aim of this study is to determine the effects of some process parameters on solid properties, especially on the particle-size distribution, structure, dispersion, purity and solubility of the solid. the following process parameters are studied at different values : reactants addition mode (slow, fast and parallel addition), reactant molalities $\left(\left[\mathrm{MgCl}_{2}, 6 \mathrm{H}_{2} \mathrm{O}\right]=0.73,1.47\right.$, 1.94, 2.21 and 2.94 mol.kg ${ }^{-1} ;\left[\mathrm{Na}_{2} \mathrm{SiO}_{3}, 5 \mathrm{H}_{2} \mathrm{O}\right]=0.71,1.43,1.88,2.14$ and $\left.2.86 \mathrm{~mol} . \mathrm{kg}^{-1}\right), \mathrm{HCl}$ molality $\left(0.50,1.00\right.$ and $\left.2.00 \mathrm{~mol} . \mathrm{kg}^{-1}\right)$, temperature $\left(20,40\right.$ and $\left.50^{\circ} \mathrm{C}\right)$ and ultrasound $(0.0$ and $34.5 \mathrm{~W})$ during the precipitation in the mixing system.

At the end of the synthesis, the suspension was filtered with a Büchnermembrane system. The cake was then washed four times with water, so that the salt $(\mathrm{NaCl})$ formed during the synthesis could be eliminated. After the first filtration and after every washing step, the conductivity of the eliminated water was measured. The conductivity of $\mathrm{NaCl}$ solutions at different concentrations was first measured for calibration purposes. Then, from the conductivity of each batch of eliminated water, the residual quantity of $\mathrm{NaCl}$ in the water was calculated. The conductivity of the last batch of eliminated water (after the fourth washing step) was about $0.3 \mathrm{mS} . \mathrm{cm}^{-1}$, which corresponds to 0.4 g. $\mathrm{L}^{-1}$ of $\mathrm{NaCl}$. The product was then dried at $100^{\circ} \mathrm{C}$ for 15 hours in a drying oven. During this step, the water evaporation in a stagnant environment with the high specific surface of primary particles created crystalline bonds between particles, leading to strong agglomerates. The mean diameter of these agglomerates was higher than the mean diameter measured during the synthesis. In order to break down these agglomerates and thus be able to analyse the dry solid, it was ground by a laboratory impact mill (coffee mill) for 20 seconds.

In order to try to prevent agglomeration during the drying step in the oven, three other drying techniques were tested : freeze-drying, spray-drying and drying by extraction by supercritical $\mathrm{CO}_{2}$. Before being freeze-dried, the humid solid was dispersed in water after the washing steps. The solid mass 


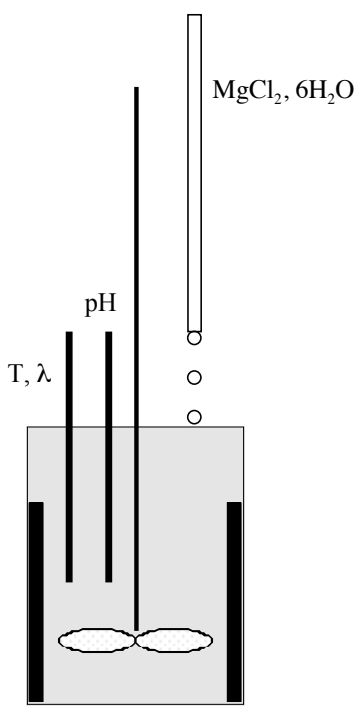

$\mathrm{Na}_{2} \mathrm{OSiO}_{2}, 5 \mathrm{H}_{2} \mathrm{O}$

(a)

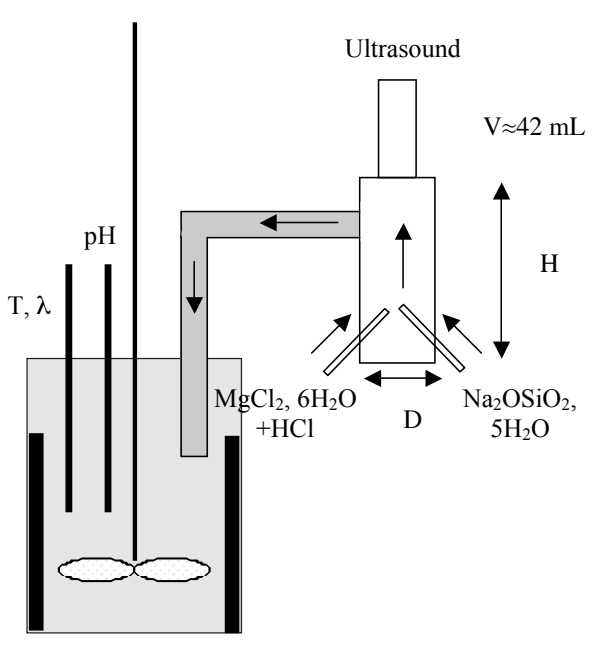

(b)

Figure 2: Experimental design of slow addition (a) and of parallel addition by a mixing system (b). 
fraction was about $20 \%$ in the suspension. The suspension was frozen at $23.6{ }^{\circ} \mathrm{C}$. The freeze-drying of the suspension occurred at $30{ }^{\circ} \mathrm{C}$ and $0.1 \mathrm{mbar}$. This step lasted about 70 hours.

In order to be spray-dried, the humid solid was also dispersed in water after the washing steps. The solid mass fraction in this case was about $10 \%$ in the suspension. Water was evaporated during the spray-drying of the suspension. Air entered the drying process at $250{ }^{\circ} \mathrm{C}$ and left at about $92-$ $98^{\circ} \mathrm{C}$. The suspension flow rate was between 1 and $1.5 \mathrm{~L} . \mathrm{h}^{-1}$. Solid and air were then separated by a cyclon.

Drying by extraction by supercritical $\mathrm{CO}_{2}$ makes it possible to eliminate the washing solvent. Beyond its critical point $\left(31.3{ }^{\circ} \mathrm{C}\right.$ and 73.9 bar [10]), $\mathrm{CO}_{2}$ is in a supercritical phase. Its properties (density, viscosity, etc.) are between liquid properties and gas properties. The solvent power of $\mathrm{CO}_{2}$ depends on its temperature and its pressure. $\mathrm{CO}_{2}$ can be used in order to dissolve the washing solvent and separate it from the solid. As water is not very miscible with supercritical $\mathrm{CO}_{2}$, ethanol was chosen as a washing solvent instead of water. After the last washing step with water, the solid was washed with ethanol and then filtered.The humid solid was then dried by extraction of ethanol by supercritical $\mathrm{CO}_{2}$ at $40{ }^{\circ} \mathrm{C}$ and 110 bar.

\subsubsection{Evaluation of the properties of synthetic magnesium silicate}

Suspension and synthesized powders were submitted for physico-chemical properties evaluation.

\section{Particle-size distributions}

Samples were taken of the suspension to be analysed by the dynamic light scattering technique using a Malvern Mastersizer 2000. This enables particle-size distribution to be followed during the synthesis. The suspension was diluted with water in the cell of the granulometer. Ultrasound (about $3 \mathrm{~mW}$ ) was applied during the size measurement. Figure 3 shows the influence of ultrasound applied during the size analysis of particle-size distribution. After ultrasound had been used, the size distribution shifted towards fine particles. This must be due to the ultrasound, which causes disaggregation of the solid. After two minutes of ultrasound, the particles-size distribution no longer changed. For this reason, every sample was subjected to ultrasound for two minutes. The span of the particle-size distribution was defined by the following equation (Eq. 2) :

$$
\operatorname{span}=\frac{d_{90}-d_{10}}{d_{50}}
$$


where $d_{10}, d_{50}$ and $d_{90}$ are respectively particle diameters at cumulative $10 \%$, $50 \%$ and $90 \%$ from fine particle side of the cumulative-volume particle-size distribution.

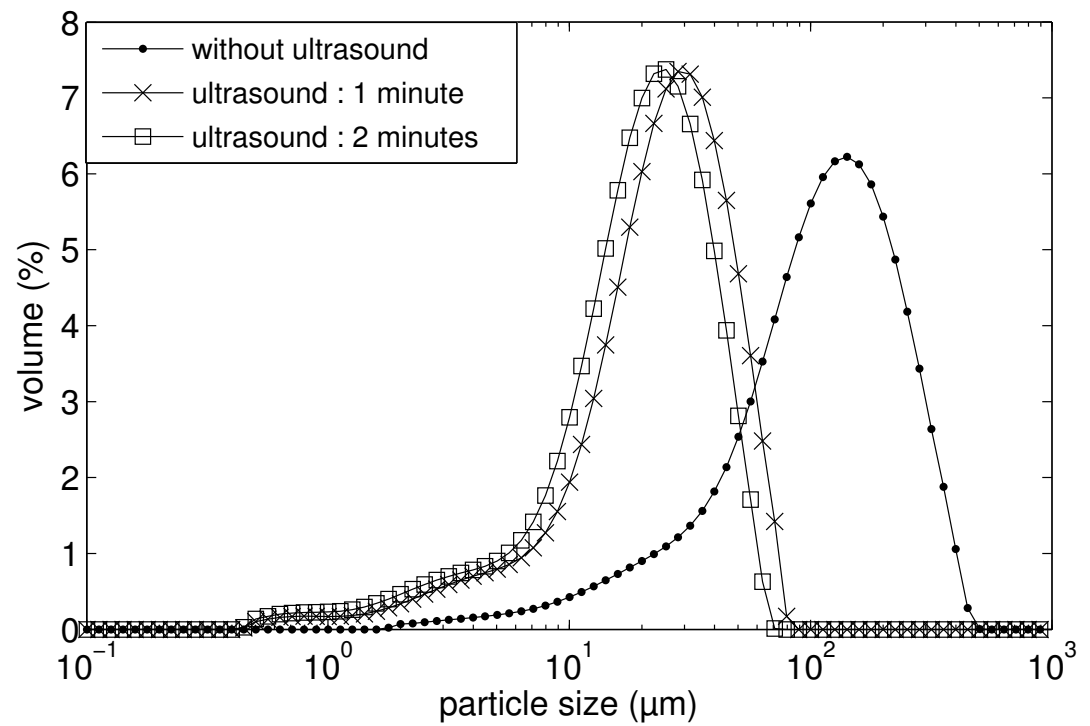

FIGURE 3: Influence of ultrasound applied during the size analysis on particle-size distribution (addition mode : slow addition, $\left[\mathrm{MgCl}_{2}, 6 \mathrm{H}_{2} \mathrm{O}\right]=1.47 \mathrm{~mol} \cdot \mathrm{kg}^{-1}, \mathrm{~T}=20^{\circ} \mathrm{C}$, samples taken after 210 minutes).

Fig. 4 shows particle-size distribution evolution during the synthesis. The distribution does not vary as a function of time. So particle-size distribution does not change during the synthesis. In this study, all particle-size distribution measurements were taken at the end of the synthesis, after 210 minutes.

\section{Solid morphology}

In order to define surface morphology and the stage of agglomeration of the particles, the dried products were examined by scanning electron microscopy (SEM-FEG, Philips XL 30).

\section{Density}

The density of dried products is measured using a Micrometrics AccuPyc 1330 helium pycnometer. 


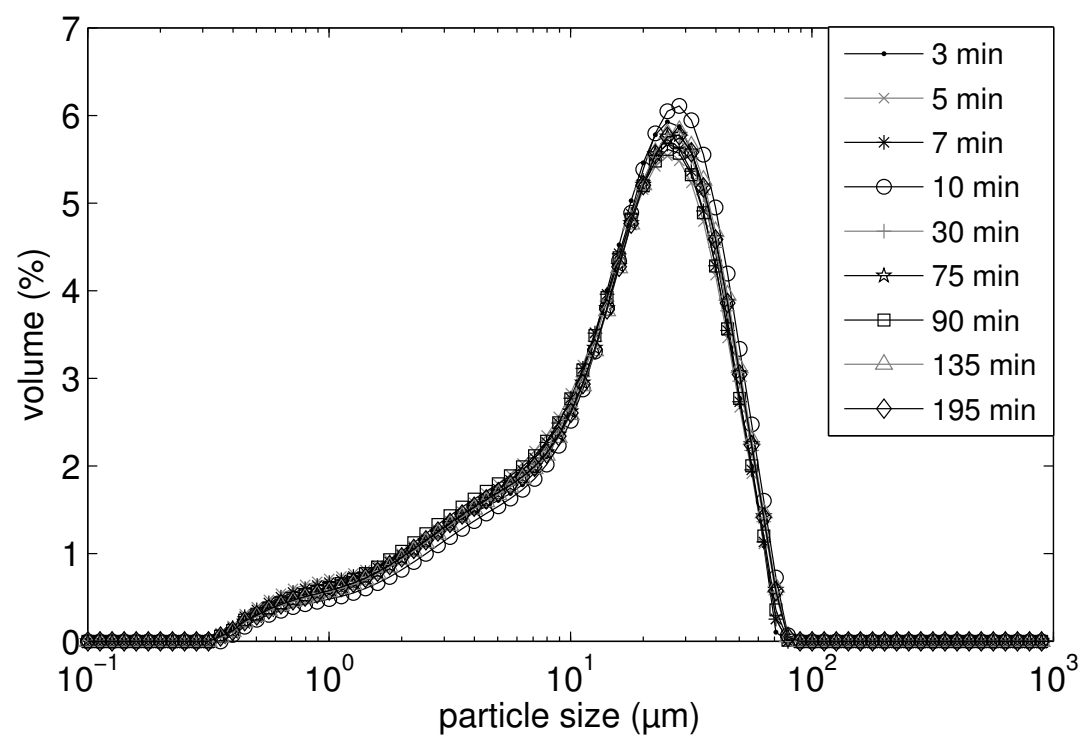

FIGURE 4: Evolution of particle-size distribution during the synthesis (addition mode : mixing system and ultrasound, $\left.\left[\mathrm{MgCl}_{2}, 6 \mathrm{H}_{2} \mathrm{O}\right]=1.47 \mathrm{~mol} \cdot \mathrm{kg}^{-1}, \mathrm{~T}=20^{\circ} \mathrm{C}\right)$.

\section{Specific surface}

the BET surface area of the dried products was estimated using a Micrometrics ASAP 2010 apparatus and by obtaining nitrogen adsorption and desorption isotherms. The degassing was carried out at $250^{\circ} \mathrm{C}$ for 24 hours. Mesoporous volume was calculated by using the Barret, Joyner and Halenda method (B.J.H. method) on the desorption field of the adsorption/desorption isotherm. Microporous volume was calculated by using the t-plot method on the adsorption field of the adsorption/desorption isotherm.

\section{Crystalline structure}

Analyses by X-Ray diffraction were also carried out on dried products using an X'Pert Philips Pan Analytical diffractometer with a $\mathrm{CuK} \alpha$ radiation source. Measurement and duration steps were respectively $2 \theta=0.0334^{\circ}$ and 50 seconds.

\section{Chemical composition of solid}

Analyses by X-Ray fluorescence spectrometry was used to calculate $\mathrm{Mg} / \mathrm{Si}$ ratio in the synthesized solid. The solid powder was mixed with lithium meta 
and tetraborate. A pearl was formed from this mixture in the Perlix'3 apparatus. A Philips (WD-XRF ) - PW2504 apparatus was used for these analyses. It is a wavelength-dispersive apparatus.

\section{Dispersion test}

Dispersion tests were undertaken to study the behaviour of the dispersed product in water. These tests, which followed the method described in patent N WO 99/28376 [11], were done in the cell of the granulometer. A dried synthetic magnesium silicate was dispersed in water. During this test, the evolution of the median diameter was measured as a function of time. At the beginning of the test, three consecutive measurements were made without ultrasound to determine the initial diameter. Then the ultrasound generation was set at a power of $100 \%$ (about $3 \mathrm{~mW}$ ). The median diameter was measured every 10 seconds for 5 minutes.

\subsubsection{Amorphous magnesium silicate solubility}

Amorphous magnesium silicate solubility was estimated from the precipitation using PHREEQC, a computer program for speciation calculations [12]. Initial molalities of species $\mathrm{Na}, \mathrm{Si}, \mathrm{Cl}$ and $\mathrm{Mg}$, total mass of water, final temperature and $\mathrm{pH}$ of the suspension and chemical equilibria constituted the input data. The program calculates activity coefficients, final activities and molalities of different species in solution, and the temperature and $\mathrm{pH}$ of the suspension with and without precipitated solid. The objective is to determine the equilibrium constant of amorphous magnesium silicate from $\mathrm{pH}$ measurements. In input data, this equilibrium constant is adjusted in order to obtain $p H^{\text {calculated }}=p H^{\text {experimental }}$ for every experiment. For this, we made the assumption that, at the end of the synthesis, after 210 minutes, the $\mathrm{pH}$ of the suspension is stable. Fig. 5 shows $\mathrm{pH}$ evolution during four different experiments (same initial reactants molalities). After 80 minutes, the $\mathrm{pH}$ is stable and its value does not vary between these four experiments. A more detailed description of this figure will be made in part 3.3.1. From this result, we assume that chemical and liquid/solid equilibria are attained at the end of the synthesis, after 210 minutes.

\section{Results and discussion}

Table 1 gives operating conditions for all synthesized solids.

Table 2 summarizes suspension and solid properties (pH after $210 \mathrm{mi}$ nutes $p H^{f}$, median diameter $d_{50}$, surface diameter $d_{32}$, density, specific sur- 


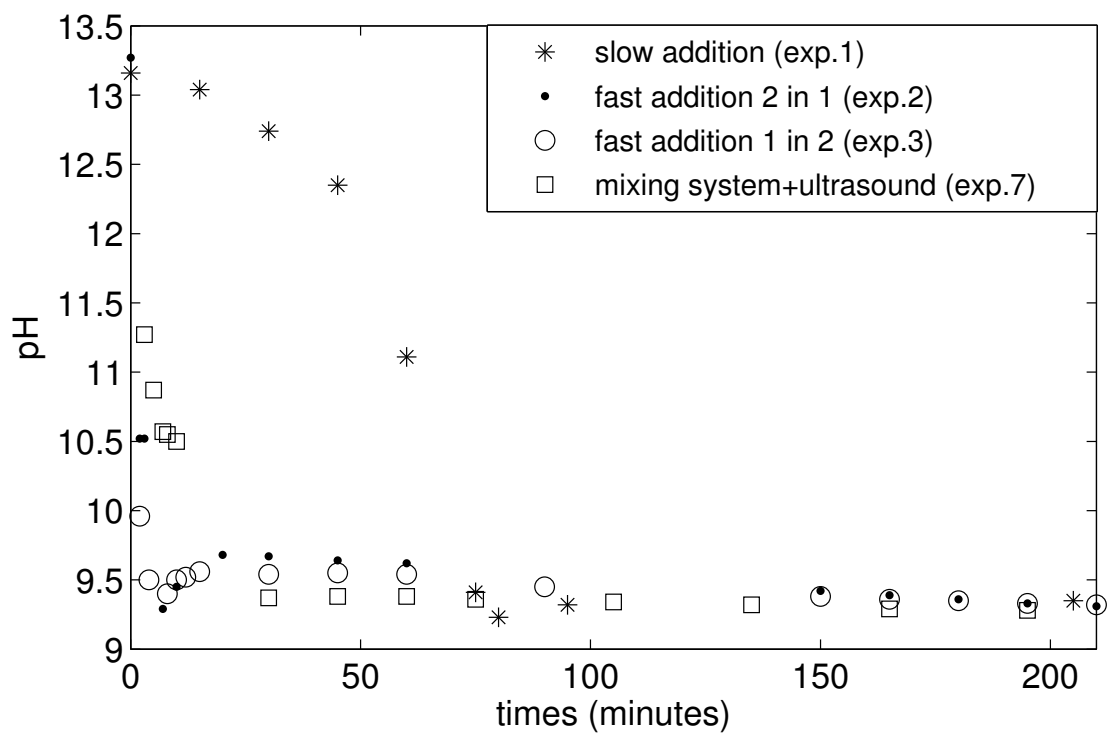

FIGURE 5: Evolution of suspension $\mathrm{pH}$ as a function of time, reactant-addition order and mode $\left(\left[\mathrm{MgCl}_{2}, 6 \mathrm{H}_{2} \mathrm{O}\right]=1.47 \mathrm{~mol} . \mathrm{kg}^{-1}, \mathrm{~T}=20^{\circ} \mathrm{C}\right)$.

face area, molar ratio $\mathrm{Mg} / \mathrm{Si}$, mass fraction of magnesium silicate) as a function of operating conditions. The calculation of mass fraction of magnesium silicate is presented in part 3.3.2. For experiments made in the same conditions of initial reactants molalities, an average value is given for the $\mathrm{pH}$ and the mass fraction of magnesium silicate. 


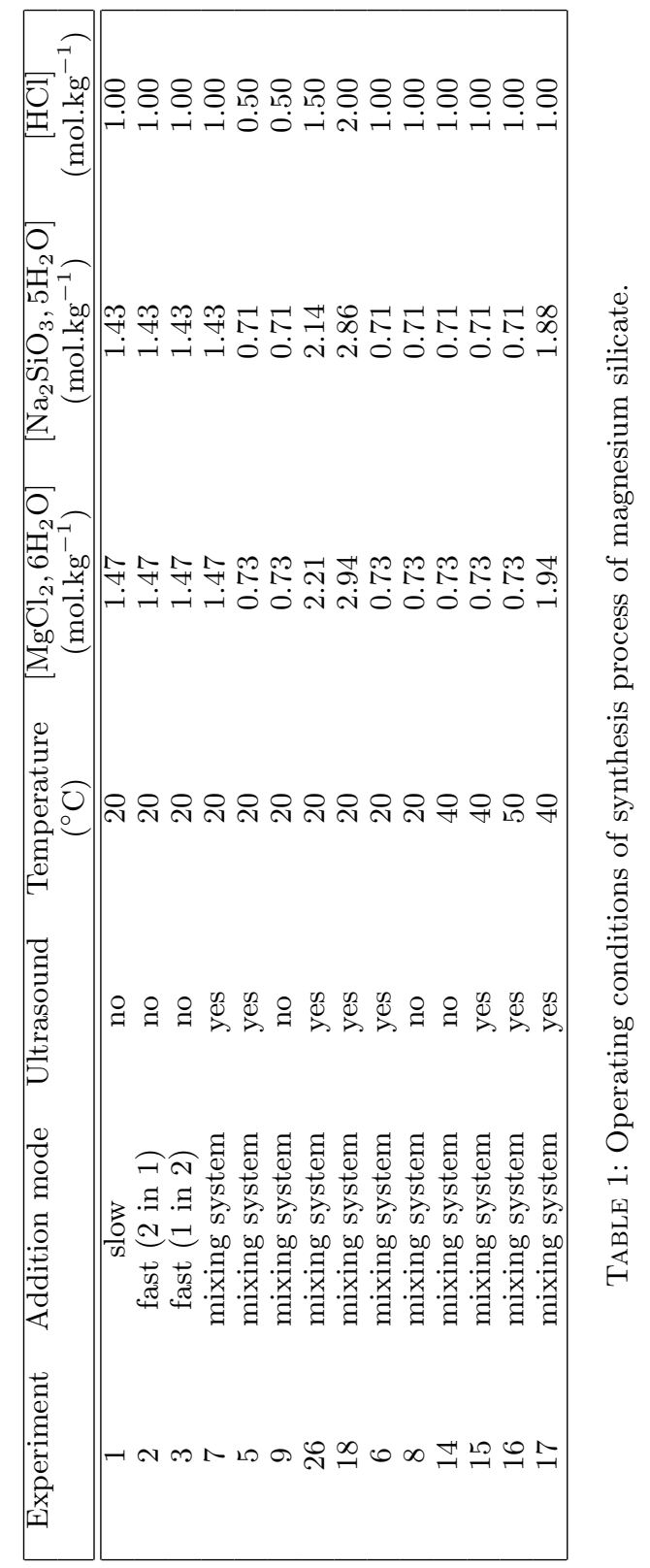




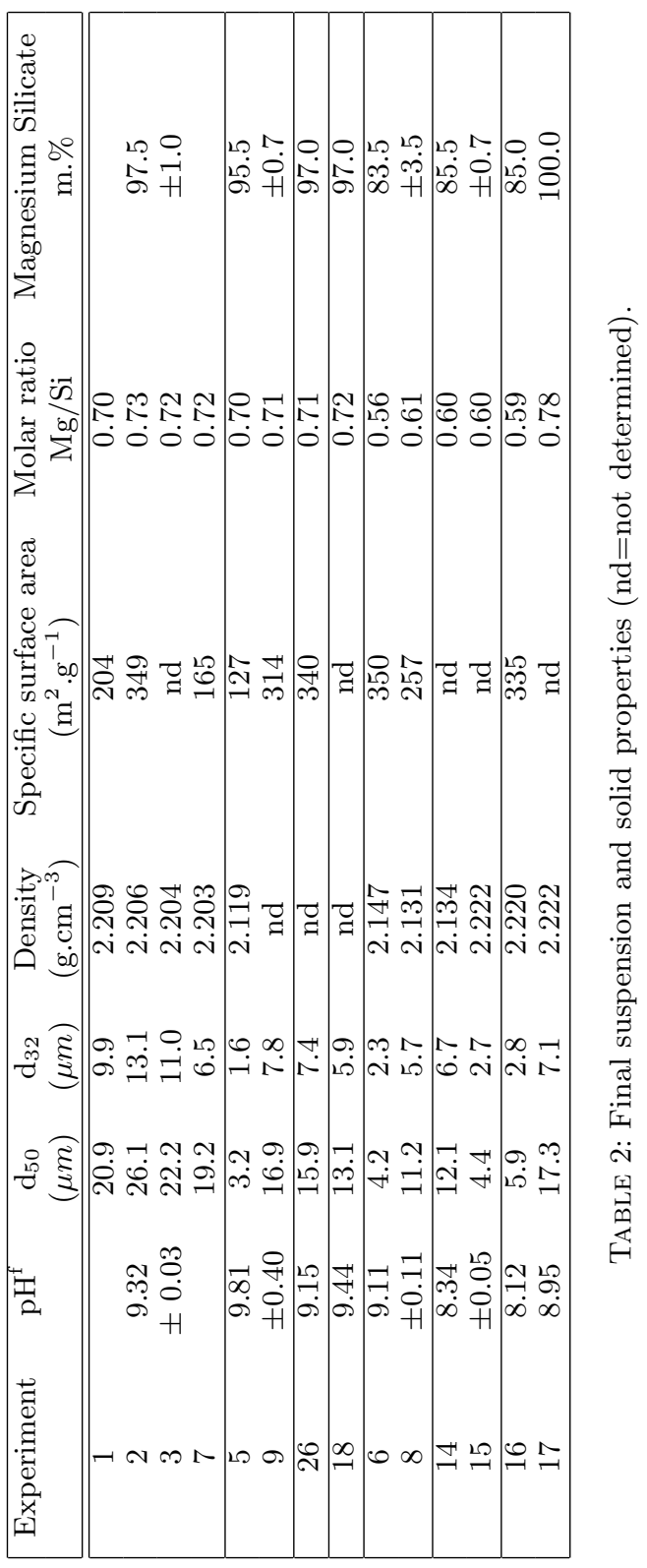




\subsection{Reproducibility of experiments}

Fig. 6 shows particle-size distributions of two identical experiments. Both experiments were done under the same conditions. Both distributions are almost identical.

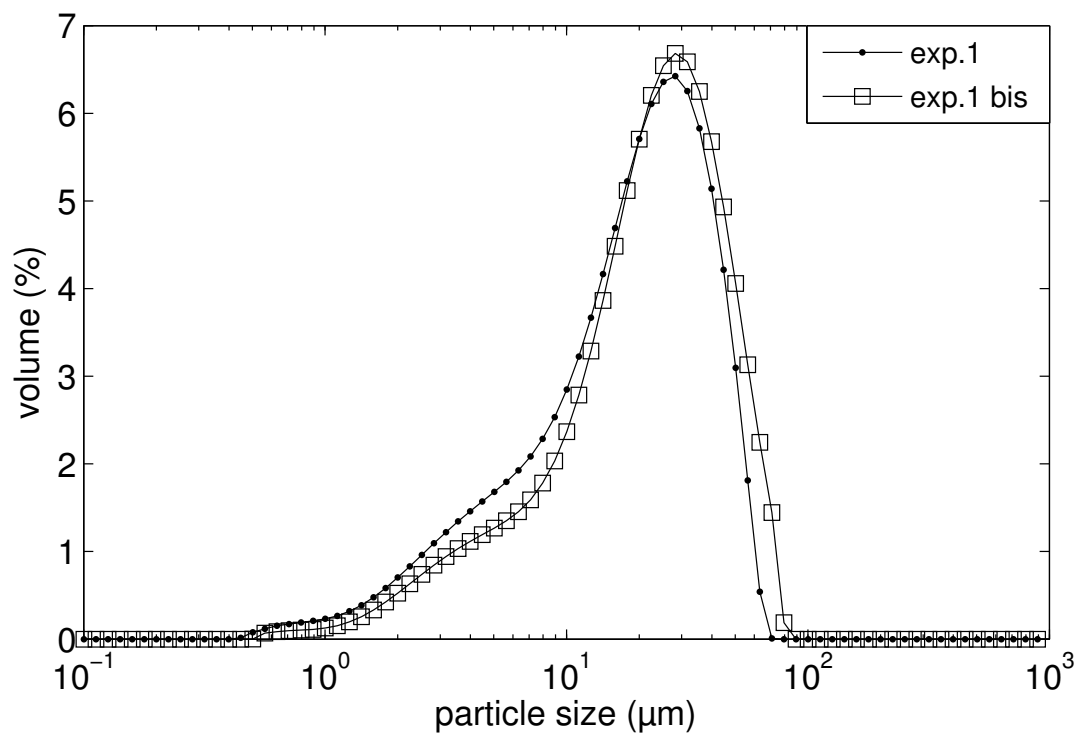

FIgURE 6: Reproducibility of experiments (addition mode : slow, $\left.\left[\mathrm{MgCl}_{2}, 6 \mathrm{H}_{2} \mathrm{O}\right]=1.47 \mathrm{~mol} \cdot \mathrm{kg}^{-1}, \mathrm{~T}=20^{\circ} \mathrm{C}\right)$.

\subsection{Crystalline structure}

Diffractograms obtained by X-Ray diffraction analyses show that all synthesized magnesium silicate solids are amorphous. The diffractogram (Fig. 7) does not present any real peak, only the appearance of a peak at $2 \theta=46.5^{\circ}$. However, it cannot be exploited because of its low intensity.

Regardless of which process parameters were studied, the product obtained by precipitation was always amorphous. These results are in compliance with the works of Ciesielczyk et al. [6, 7]. They show that precipitated magnesium silicate is amorphous and this form is independent of the precipitation temperature and addition mode.

\subsection{Purity of solid}

\subsubsection{Reactant-addition mode effect}

Regardless of the reactant-addition order and mode (slow, fast or with the mixing system and ultrasound), with the same initial reactant molali- 


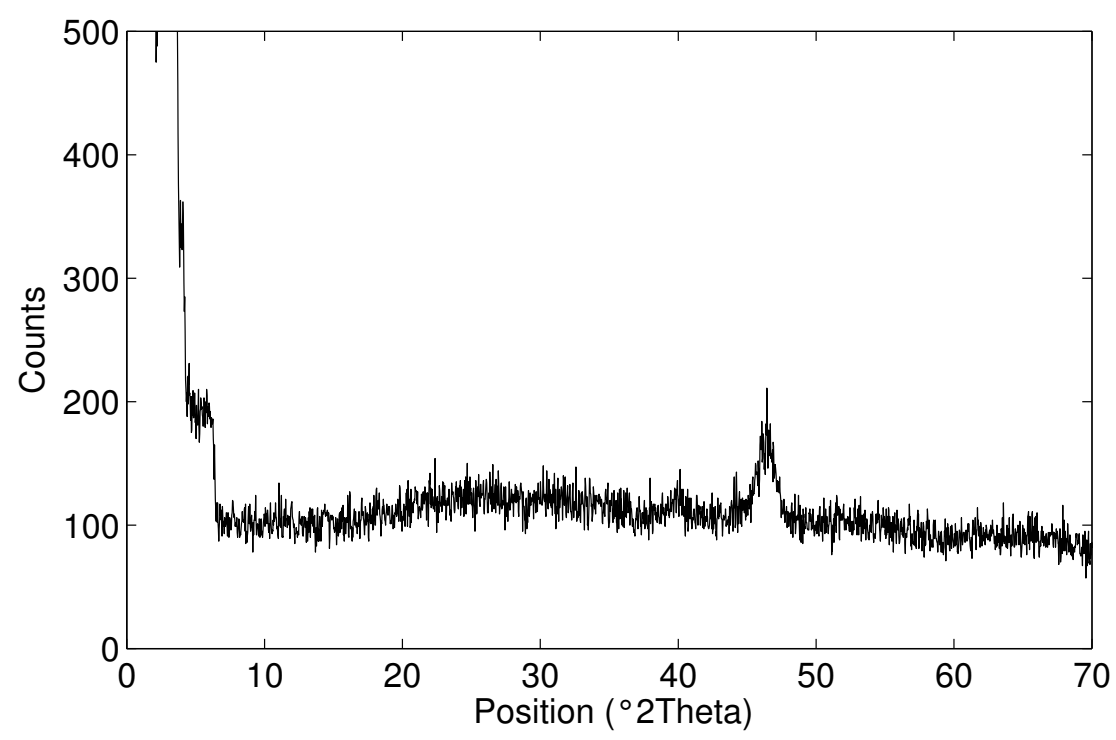

FiguRE 7: Diffractogram of a product (addition mode : parallel with mixing system and ultrasound, $\left[\mathrm{MgCl}_{2}, 6 \mathrm{H}_{2} \mathrm{O}\right]=0.73 \mathrm{~mol} \cdot \mathrm{kg}^{-1}, \mathrm{~T}=20^{\circ} \mathrm{C}$ ) obtained by X-Ray diffraction at $0.141 \mathrm{~nm}(\mathrm{Cu})$ (measurement step $2 \theta=0.0334^{\circ}$; duration step $=50$ seconds).

ties, the final $\mathrm{pH}$ in the suspension is identical (Table 2). Fig. 5 shows $\mathrm{pH}$ evolution during the synthesis for experiments $1,2,3$ and 7 . With the slow addition, initial $\mathrm{pH}$ is sodium metasilicate solution $\mathrm{pH}\left(\mathrm{pH}^{i}=13.16\right)$ and it then decreases until 80 minutes, which corresponds to the end of magnesium chloride addition. With the fast addition of reactant 2 in reactant 1 , initial $\mathrm{pH}$ is also sodium metasilicate solution $\mathrm{pH}$ and it also then decreases, but this decrease is faster than with the slow addition because, in this case, magnesium chloride solution is instantaneously added. With the opposite reactant-addition order, the initial value is different because it is equal to magnesium chloride solution $\mathrm{pH}\left(\mathrm{pH}^{i}=0.06\right)$ but $\mathrm{pH}$ evolution and the final value do not change. With the mixing system and ultrasound, the initial $\mathrm{pH}$ value is false because the $\mathrm{pH}$ probe isn't totally immersed in the suspension. Despite the change of reactant-addition order and mode, after 80 minutes, the suspension $\mathrm{pH}$ of four experiments is constant and identical.

As has been previously stated, we assume from this result that chemical and liquid-solid equilibria are attained at the end of each synthesis ( $>80$ minutes). 


\subsection{2. $\mathrm{HCl}$ molality effect}

Lèbre [5] worked with the following molalities : $\left[\mathrm{MgCl}_{2}, 6 \mathrm{H}_{2} \mathrm{O}\right]=1.47$ mol.kg ${ }^{-1},\left[\mathrm{Na}_{2} \mathrm{SiO}_{3}, 5 \mathrm{H}_{2} \mathrm{O}\right]=1.43 \mathrm{~mol} . \mathrm{kg}^{-1}$ and $[\mathrm{HCl}]=1.00 \mathrm{~mol} \cdot \mathrm{kg}^{-1}$. These conditions of molalities are here called "standard" conditions. The influence of initial reactant molalities is studied in this paper, maintaining the initial molar ratio $\mathrm{Mg} / \mathrm{Si}$ at the constant value of 0.75 . Initial reactant molalities are firstly divided by $2:\left[\mathrm{MgCl}_{2}, 6 \mathrm{H}_{2} \mathrm{O}\right]=0.73 \mathrm{~mol} \cdot \mathrm{kg}^{-1}$ and $\left[\mathrm{Na}_{2} \mathrm{SiO}_{3}, 5 \mathrm{H}_{2} \mathrm{O}\right]=0.71$ mol. $\mathrm{kg}^{-1}$. Two experiments were carried out : in the first experiment, $\mathrm{HCl}$ molality was divided by 2 (in order to stay in "standard" conditions) and, in the second experiment, $\mathrm{HCl}$ molality was kept at $1.00 \mathrm{~mol} \cdot \mathrm{kg}^{-1}$ (Tab. 1, exp.5 and 6).

Both solids were analysed by XRF in order to calculate the final molar ratio $\mathrm{Mg} / \mathrm{Si}$. The solid that stemmed from synthesis with $\mathrm{HCl}$ concentration kept at 1.00 mol. $\mathrm{L}^{-1}$ did not present the right molar ratio (Tab. 2, exp.6) whereas the solid that stemmed from the synthesis with $\mathrm{HCl}$ molality divided by 2 presented a molar ratio of 0.70 , that is to say a relative difference of $6.7 \%$ with the theoretic molar ratio (exp.5).

A co-precipitation of magnesium silicate and silica could explain these results. By maintaining $\mathrm{HCl}$ molality at the constant value of $1.00 \mathrm{~mol}^{-\mathrm{L}^{-1}}$ when reactant molalities are divided by 2 , the $\mathrm{pH}$ of the suspension is lower than in "standard" conditions (Fig. 8). The amorphous silica solubility depends on the $\mathrm{pH}$ of the suspension : it decreases when the $\mathrm{pH}$ decreases, and thus the supersaturation of silica increases when the $\mathrm{pH}$ decreases $[13,14,15,16]$. Fig. 8 shows the evolution of silica solubility as a function of initial $\mathrm{HCl}$ molality, during the synthesis. The relative solubility difference between both experiments is between 16.9 and $93.3 \%$ during the synthesis. So amorphous silica does appear to precipitate in addition with amorphous magnesium silicate. The mass fraction of anhydrous amorphous magnesium silicate $w_{\text {magnesium silicate }}$ in anhydrous solids (magnesium silicate and silica) can be calculated with the molar ratio $\mathrm{Si} / \mathrm{Mg}$ :

$$
w_{\text {magnesiumsilicate }}=\frac{m_{\text {magnesiumsilicate }}}{m_{\text {tot }}\left(1-w_{w}\right)}=\frac{1}{\frac{M_{\mathrm{SiO}_{2}}}{M_{\text {magnesiumsilicate }}}(3 r-4)+1}
$$

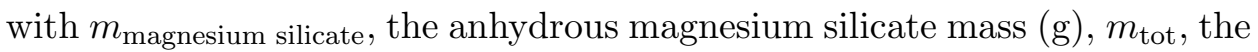
total mass of hydrous solids (g), $w_{\mathrm{w}}$, the mass fraction of water in the total hydrous solid, $M_{\mathrm{SiO}_{2}}$, the molar mass of silica (g.mol $\left.{ }^{-1}\right), M_{\text {magnesium silicate }}$, the molar mass of anhydrous magnesium silicate (g.mol ${ }^{-1}$ ) and $r$, the molar ratio $\mathrm{Si} / \mathrm{Mg}$ that is measured by XRF analysis.

Anhydrous magnesium silicate mass fractions are given in Tab. 2. For ex- 


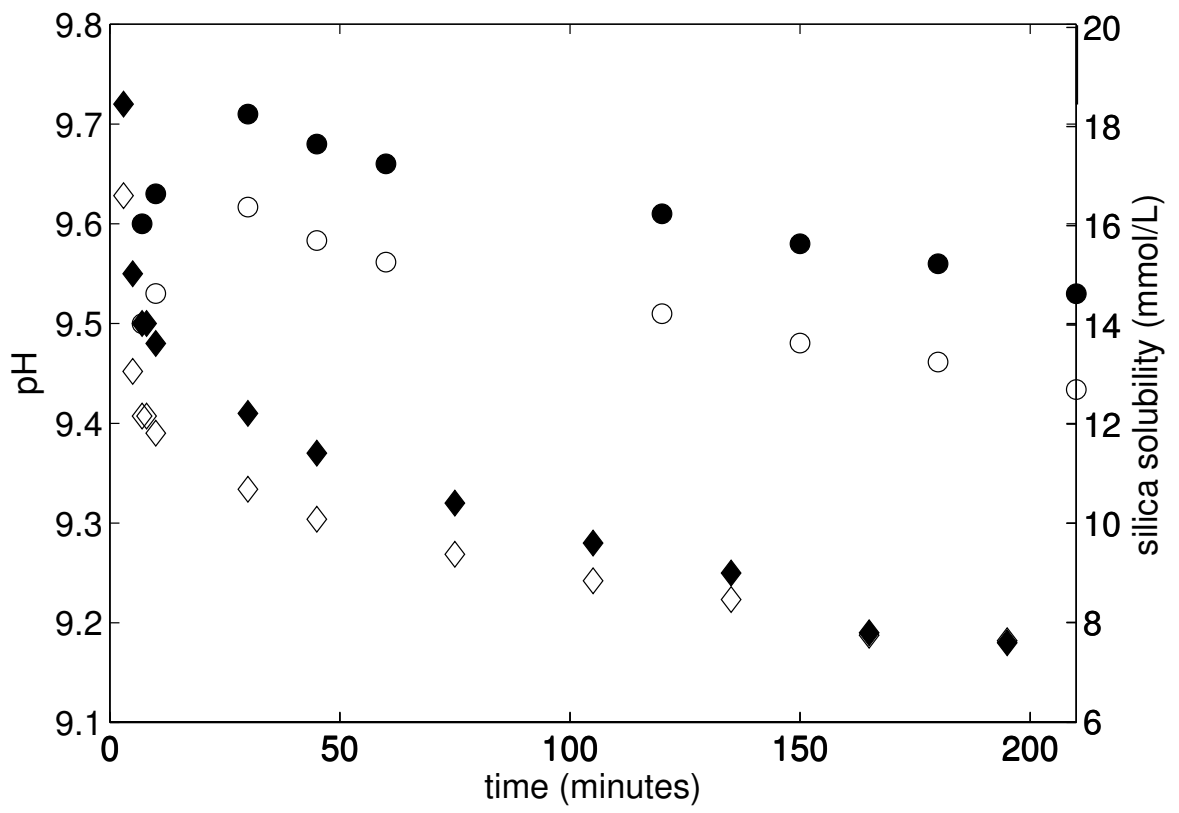

FiguRE 8: Evolution of the suspension pH (rounded symbols) and silica solubility (empty symbols) as a function of time and initial $\mathrm{HCl}$ molality. Parallel reactant addition with mixing system is used $\left(\left[\mathrm{MgCl}_{2}, 6 \mathrm{H}_{2} \mathrm{O}\right]=0.73 \mathrm{~mol} \cdot \mathrm{kg}^{-1}, \mathrm{~T}=20^{\circ} \mathrm{C}\right)$.

$\circ[\mathrm{HCl}]=0.50 \mathrm{~mol} / \mathrm{kg}(\exp .9)$, solubility

- $[\mathrm{HCl}]=0.50 \mathrm{~mol} / \mathrm{kg}(\exp .9), \mathrm{pH}$

$\diamond[\mathrm{HCl}]=1.00 \mathrm{~mol} / \mathrm{kg}(\exp .8)$, solubility

$\checkmark[\mathrm{HCl}]=1.00 \mathrm{~mol} / \mathrm{kg}(\exp .8), \mathrm{pH}$ 
periments made with $\mathrm{HCl}$ molality kept at the constant value of $1.00 \mathrm{~mol} . \mathrm{kg}^{-1}$ $\left(\left[\mathrm{MgCl}_{2}, 6 \mathrm{H}_{2} \mathrm{O}\right]=0.73 \mathrm{~mol} \cdot \mathrm{kg}^{-1}\right]$, experiments $6,8,14,15$ and 16$)$, the synthesized anhydrous solid is made up of $82 \pm 3 \%$ of magnesium silicate.

The product density seems to be independent of the studied operating conditions : $2.181 \pm 0.043$ g.cm ${ }^{-3}$ (Tab. 2) despite the relative high mass fraction of silica in some solids. The density of amorphous silica is about 2.200 g. $\mathrm{cm}^{-3}$. This value is not very different from the magnesium silicate density, which explains why no difference is observed between the density of a solid containing a lot of, or only a little silica.

\subsubsection{Ultrasound effect}

By comparing experiments made using the mixing system, with or without ultrasound during the synthesis, and with the same initial reactant molalities (Tab. 2), we can state that ultrasound has no effect on the mass fraction of magnesium silicate in the solid (Tab. 3).

\begin{tabular}{|ccc|}
\hline Experiment & Ultrasound & $\begin{array}{c}\text { Magnesium Silicate } \\
\text { m. } \%\end{array}$ \\
\hline 5 & yes & 95 \\
9 & no & 96 \\
\hline 14 & no & 86 \\
15 & yes & 85 \\
\hline
\end{tabular}

TABLE 3: Mass fraction of magnesium silicate as a function of the use of ultrasound during the synthesis.

\subsection{Solubility of amorphous magnesium silicate}

During the co-precipitation of magnesium silicate $\mathrm{Si}_{4} \mathrm{Mg}_{3} \mathrm{O}_{11}, \mathrm{nH}_{2} \mathrm{O}$ and silica $\mathrm{SiO}_{2}$, different chemical equilibria intervene (Tab. 4). 


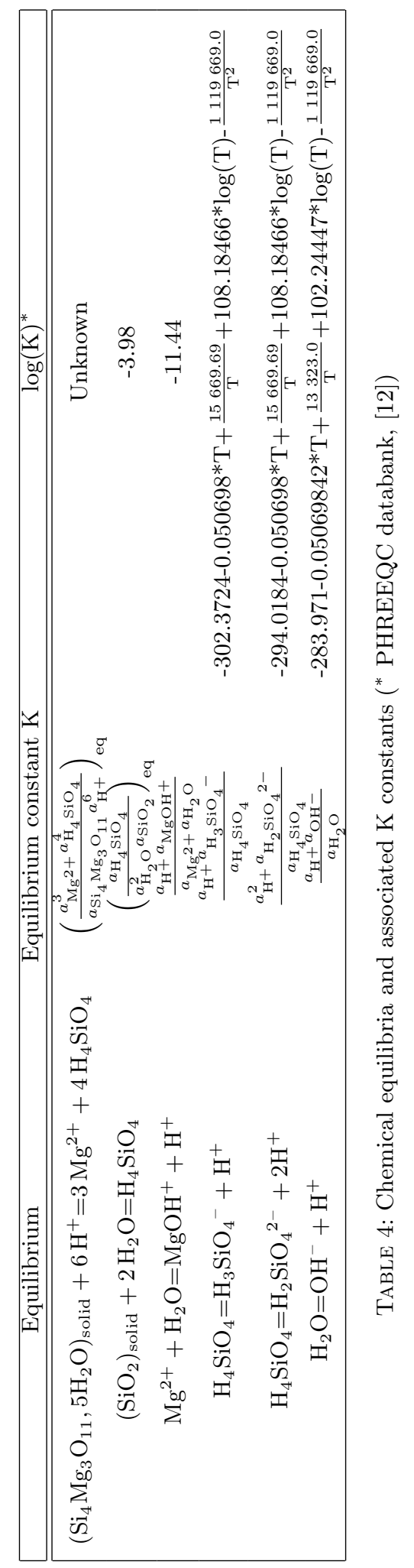


The hydration rate of magnesium silicate, which is represented by $\mathrm{nH}_{2} \mathrm{O}$ in the chemical formula of the solid, was previously determined in order to write chemical equilibria and calculate molalities of the species in solution. The dry solid was first analysed by thermogravimetric analysis (TGA) at $200^{\circ} \mathrm{C}$ for 16 hours in order to estimate total hydration of the solid $(21.1 \%)$, surface hydration due to the residual water after the drying step $(2.3 \%)$ and finally the hydration rate $(18.8 \%)$. Then the solids were dried at $550^{\circ} \mathrm{C}$ for 18 hours. By calculating the solid weight loss and subtracting the mass fraction of surface hydration, the moles number of the water was estimated. The value of $\mathrm{n}$ was between 4.6 and 5.6. An average value of 5 was chosen for chemical equilibria calculations.

The following species are in the solution : $\mathrm{H}_{4} \mathrm{SiO}_{4}, \mathrm{H}_{3} \mathrm{SiO}_{4}{ }^{-}, \mathrm{H}_{2} \mathrm{SiO}_{4}{ }^{2-}$, $\mathrm{Mg}^{2+}, \mathrm{MgOH}^{+}, \mathrm{H}^{+}$and $\mathrm{OH}^{-}$

$a_{i}$ is the activity of the species $i$ in the solution. It is calculated from the following equation :

$$
a_{i}=\gamma_{i}[i]
$$

with, $\gamma_{i}$ the activity coefficient and $[i]$ the molality $\left(\right.$ mol. $\mathrm{kg}^{-1}$ of water) of the species $i$ in the solution.

The activity coefficient $\gamma_{i}$ is calculated from Debye and Hückel's law :

$$
\log _{10}\left(\gamma_{i}\right)=\frac{-A z_{i}^{2} \sqrt{I}}{1+B a^{0} \sqrt{I}}+b I
$$

$z_{i}$ is the load of the species $i, I$ is the ionic strength of the suspension, $a^{0}$ and $b$ are constants that depend on the species $i, A$ and $B$ are constants that depend on temperature and are calculated from the following equations:

$$
A=9.37 e^{-4} * T+4.86 e^{-1}
$$

and :

$$
B=2 e^{-3} * T+3.34
$$

If the species $i$ is non-ionic, the equation 5 becomes :

$$
\log _{10}\left(\gamma_{i}\right)=0.1 I
$$

If constants $a^{0}$ and $b$ are unknown, the activity coefficient is calculated from Davies'equation :

$$
\log _{10}\left(\gamma_{i}\right)=-A z_{i}^{2}\left(\frac{\sqrt{I}}{1+\sqrt{I}}-0.3 I\right)
$$


Magnesium silicate $\mathrm{Si}_{4} \mathrm{Mg}_{3} \mathrm{O}_{11}, 5 \mathrm{H}_{2} \mathrm{O}$ is supposed to be pure so its activity $a_{\mathrm{Si}_{4}} \mathrm{Mg}_{3} \mathrm{O}_{11}$ is equal to 1 .

Water activity $a_{\mathrm{H}_{2} \mathrm{O}}$ is calculated from Raoult's equation [17] :

$$
a_{\mathrm{H}_{2} \mathrm{O}}=1-0,017 \sum_{i}^{N}[i]
$$

with $i$, the species in solution and $N$, the number of ionic species in the solution.

Chemical equilibria are calculated with the computer program PHREEQC by resolving the system of the following equations : electroneutrality, mass balances on species, ionic strength and water activity.

The adjustment of the equilibrium constant of amorphous magnesium silicate makes it possible to calculate the final $\mathrm{pH}$ of the suspension in relation to the experimental $\mathrm{pH}$ of the suspension. Fig. 9 shows calculated $\mathrm{pH}$ versus final experimental $\mathrm{pH}$ for different experiments. The relative difference between calculated and experimental values is between 0.04 and $0.22 \%$.

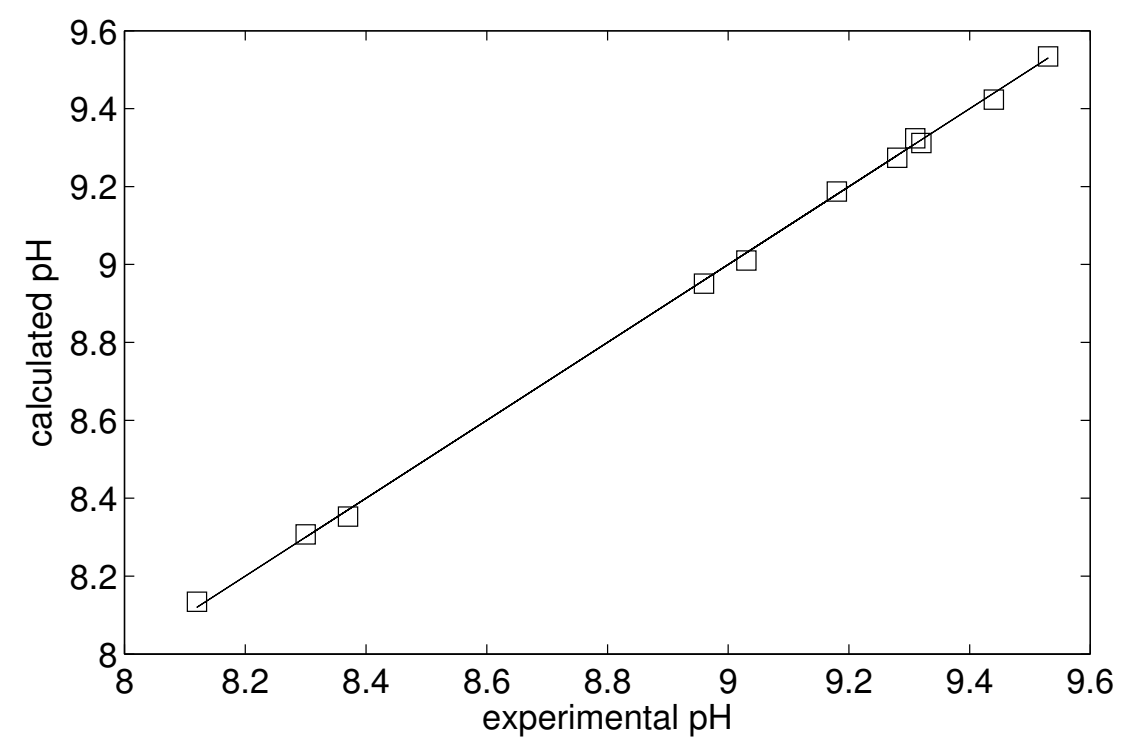

Figure 9: Calculated pH versus experimental pH.

Fig. 10 shows calculated moles number of magnesium silicate and silica versus experimental values that were obtained from XRF analysis on the dry solid. The absolute difference between calculated and experimental values 
is between 0.06 and $1.09 \%$ for magnesium silicate and between 0.03 and $4.32 \%$ for silica.

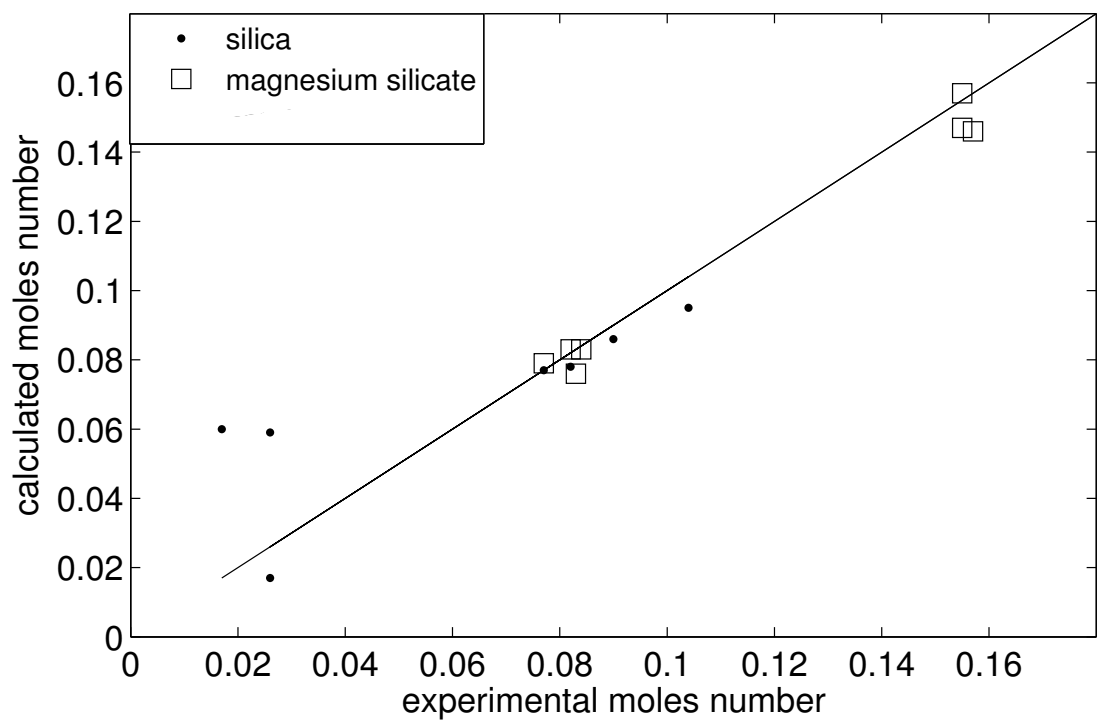

FIGURE 10: Moles numbers of silica and magnesium silicate calculated with PHREEQC versus experimental values calculated from molar ratio $\mathrm{Mg} / \mathrm{Si}$.

The equilibrium constant of magnesium silicate is calculated as a function of the temperature (Fig. 11). It is given by the following equation :

$$
\log K_{1}=-0.2399 * T+108.82
$$

\subsection{Effects of process parameters on particle-size distributions}

\subsubsection{Reactant-addition mode}

Particle-size distributions (Fig. 12) show there is an influence of the reactant-addition mode. With slow and fast additions, particle-size distributions have approximately the same span ( $\operatorname{span}=1.949$ for the slow addition and 1.799 for the fast addition) but with the addition by the mixing system and ultrasound, the particle-size distribution is larger $(\operatorname{span}=2.239)$ and is composed of smaller particles under $7 \mu \mathrm{m}$. With the fast addition, particle-size distribution shows fewer agglomerates under $10 \mu \mathrm{m}$ but more agglomerates between 10 and $100 \mu \mathrm{m}$. These differences may be due to the micromixing effect. 


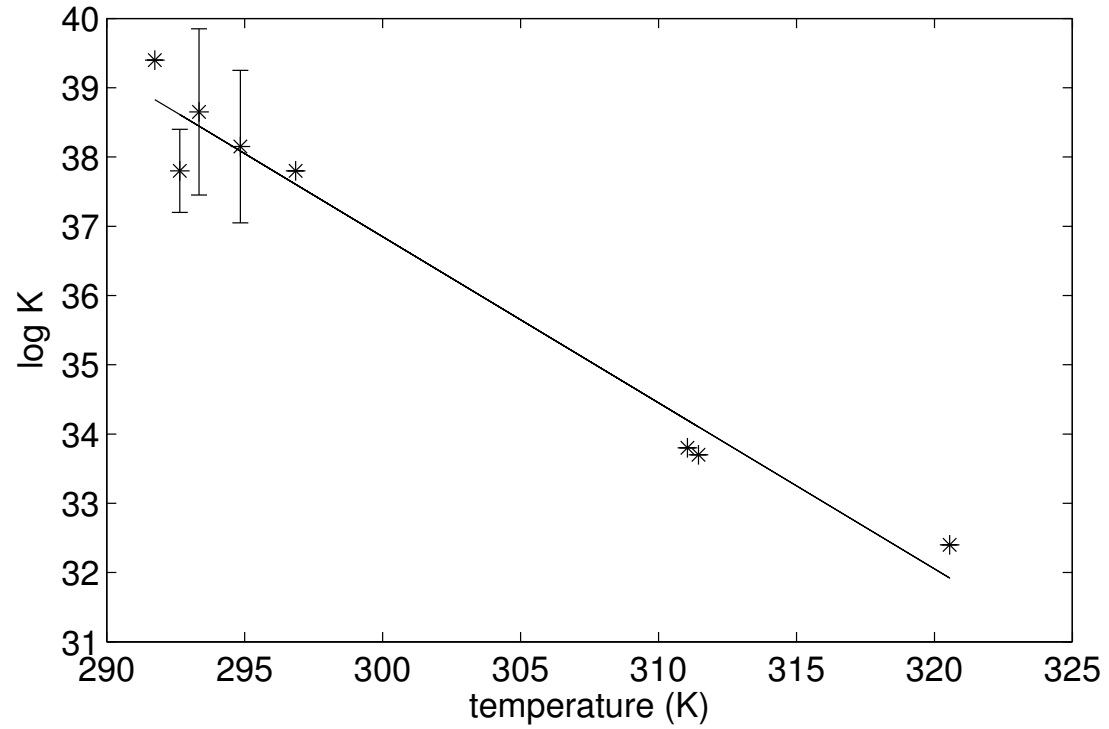

FIGURE 11: Evolution of equilibrium constant of magnesium silicate as a function of temperature.

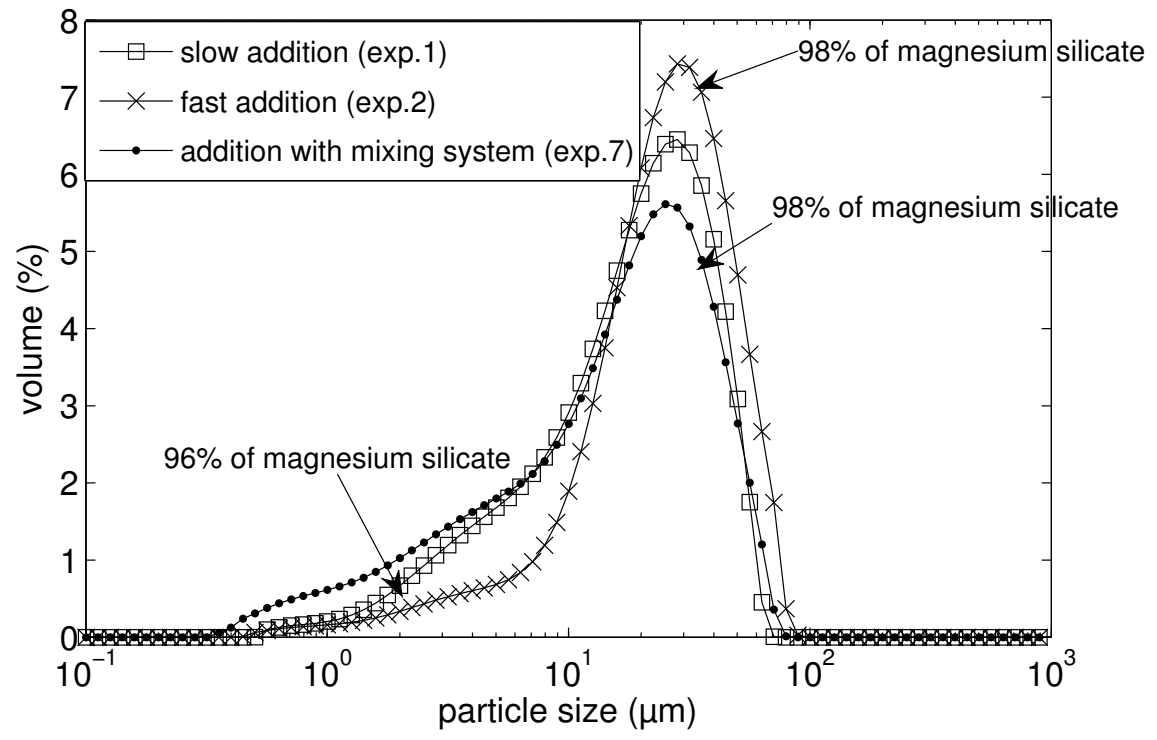

Figure 12: Particle-size distributions as a function of addition modes $\left(\left[\mathrm{MgCl}_{2}, 6 \mathrm{H}_{2} \mathrm{O}\right]=1.47 \mathrm{~mol} \cdot \mathrm{kg}^{-1}, \mathrm{~T}=20^{\circ} \mathrm{C}\right)$. 
SEM analyses (Fig. 13) confirm these observations : product synthesized with the mixing system and ultrasound is made up of smaller particles or agglomerates.

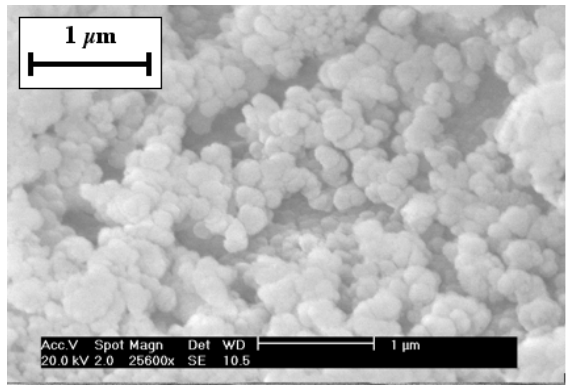

(a) $\mathrm{x} 25600$

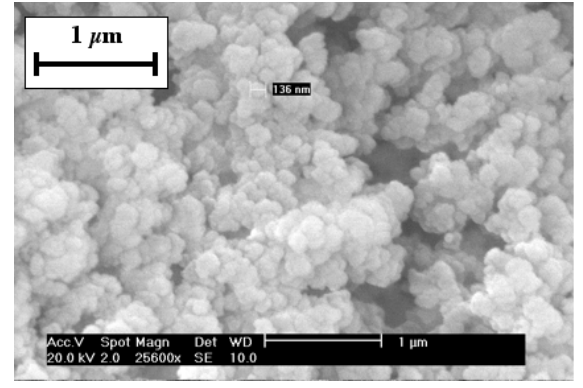

(b) $\mathrm{x} 25600$

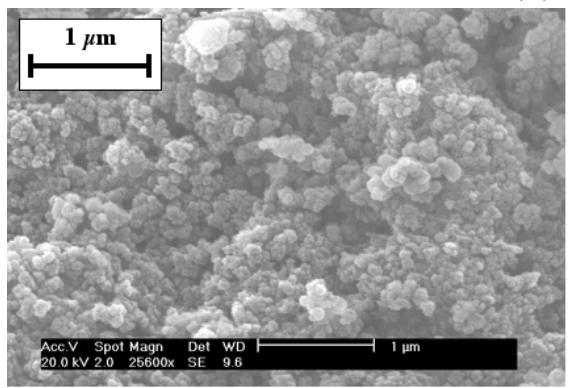

(c) $\mathrm{x} 25600$

FIGURE 13: SEM analyses of products synthesized by slow addition (a), fast addition (b) and with the mixing system and ultrasound (c) $\left(\left[\mathrm{MgCl}_{2}, 6 \mathrm{H}_{2} \mathrm{O}\right]=1.47 \mathrm{~mol}^{\mathrm{kg}} \mathrm{kg}^{-1}, \mathrm{~T}=20{ }^{\circ} \mathrm{C}\right)$.

Thus, the addition mode using the mixing system was chosen for the remainder of the study because it gives better homogeneity of the suspension during the precipitation and therefore better homogeneity of the solid, as well as probably giving smaller primary agglomerates.

\subsubsection{Initial reactant molalities}

In some ranges of initial reactant molalities, particle-size distribution is strongly influenced. Between $\left[\mathrm{MgCl}_{2}, 6 \mathrm{H}_{2} \mathrm{O}\right]=0.73 \mathrm{~mol} \cdot \mathrm{kg}^{-1}$ and $\left[\mathrm{MgCl}_{2}, 6 \mathrm{H}_{2} \mathrm{O}\right]=1.47$ mol. $\mathrm{kg}^{-1}$, with the other process conditions being the same, distribution clearly shifts towards large sizes (Fig. 14). Over $1.47 \mathrm{~mol} . \mathrm{kg}^{-1}$, particle-size distribution does not vary a lot (Fig. 14).

The differences between $\left[\mathrm{MgCl}_{2}, 6 \mathrm{H}_{2} \mathrm{O}\right]=0.73 \mathrm{~mol} \cdot \mathrm{kg}^{-1}$ and $\left[\mathrm{MgCl}_{2}, 6 \mathrm{H}_{2} \mathrm{O}\right]=1.47$ mol. $\mathrm{kg}^{-1}$ are explained by the increase in the supersaturation ratio of $S_{\text {magnesiumsilicate }}$ and $S_{\text {silica }}$ at high molalities (Tab. 5). The nucleation rate also increases, 


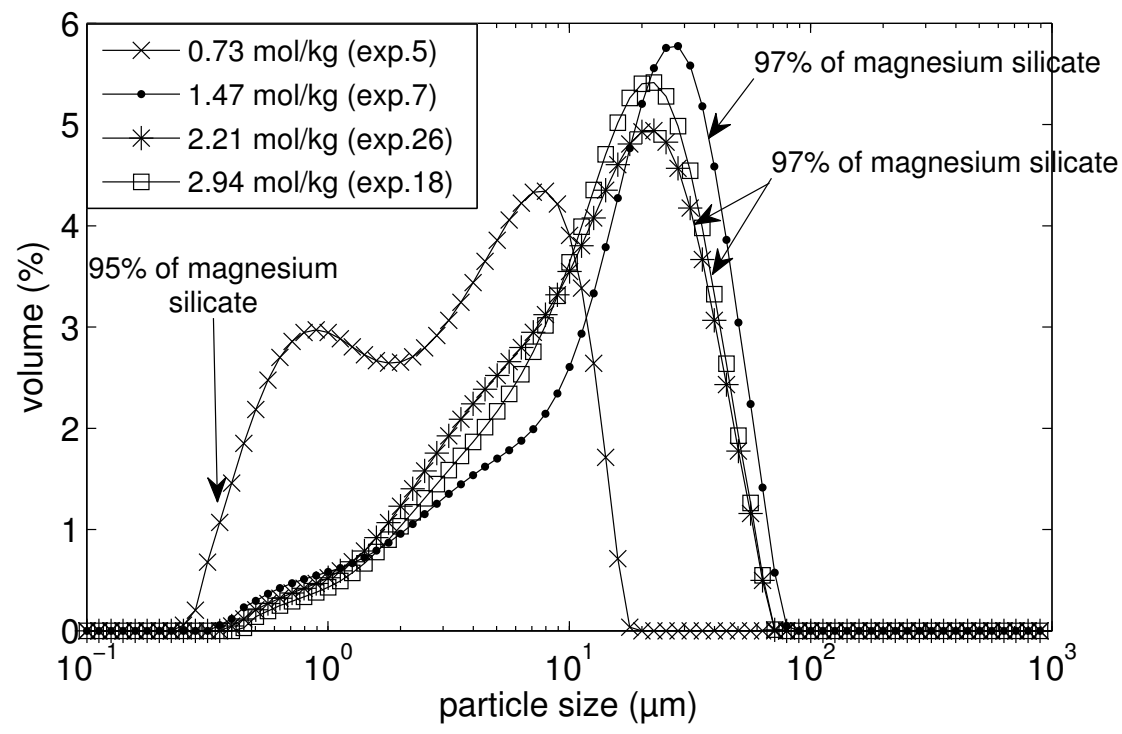

Figure 14: Particle-size distributions as a function of reactant molalities. Parallel reactant addition with mixing system and ultrasound are used $\left(\mathrm{T}=20^{\circ} \mathrm{C}\right)$.

\begin{tabular}{|cccc|}
\hline Experiment & $\begin{array}{c}{\left[\mathrm{MgCl}_{2}, 6 \mathrm{H}_{2} \mathrm{O}\right]} \\
\left(\mathrm{mol}_{\mathrm{kg}}{ }^{-1}\right)\end{array}$ & $\mathrm{S}_{\text {magnesium silicate }}^{*}$ & $\mathrm{~S}_{\text {silica }}^{*}$ \\
\hline 5 & 0.73 & $9.12 \mathrm{e}^{19}$ & 1.41 \\
7 & 1.47 & $8.71 \mathrm{e}^{22}$ & 3.63 \\
\hline
\end{tabular}

TABLE 5: Effect of initial reactants molalities on supersaturation ratio ( ${ }^{*}$ PHREEQC calculations).

so more fine particles are formed. The increase in the number of particles causes the increase in the agglomeration phenomenon. This explains why distribution shifts towards large particles at high concentrations.

Therefore, according to Zauner and Jones [18], by increasing molalities and thus supersaturation, primary particles are smaller. This result has been confirmed by Baldyga, Makowski, and Orciuch [19]. So by increasing initial molalities it would be possible to synthesize smaller particles but this would also increase agglomeration.

\subsubsection{Initial $\mathrm{HCl}$ molality}

$\mathrm{HCl}$ molality presents a slight influence on particle-size distributions : when $[\mathrm{HCl}]=1.00 \mathrm{~mol} \cdot \mathrm{kg}^{-1}$, there are more fine particles even if the width of distributions is almost the same regardless of $\mathrm{HCl}$ molality (Fig. 15, Fig. 16). 


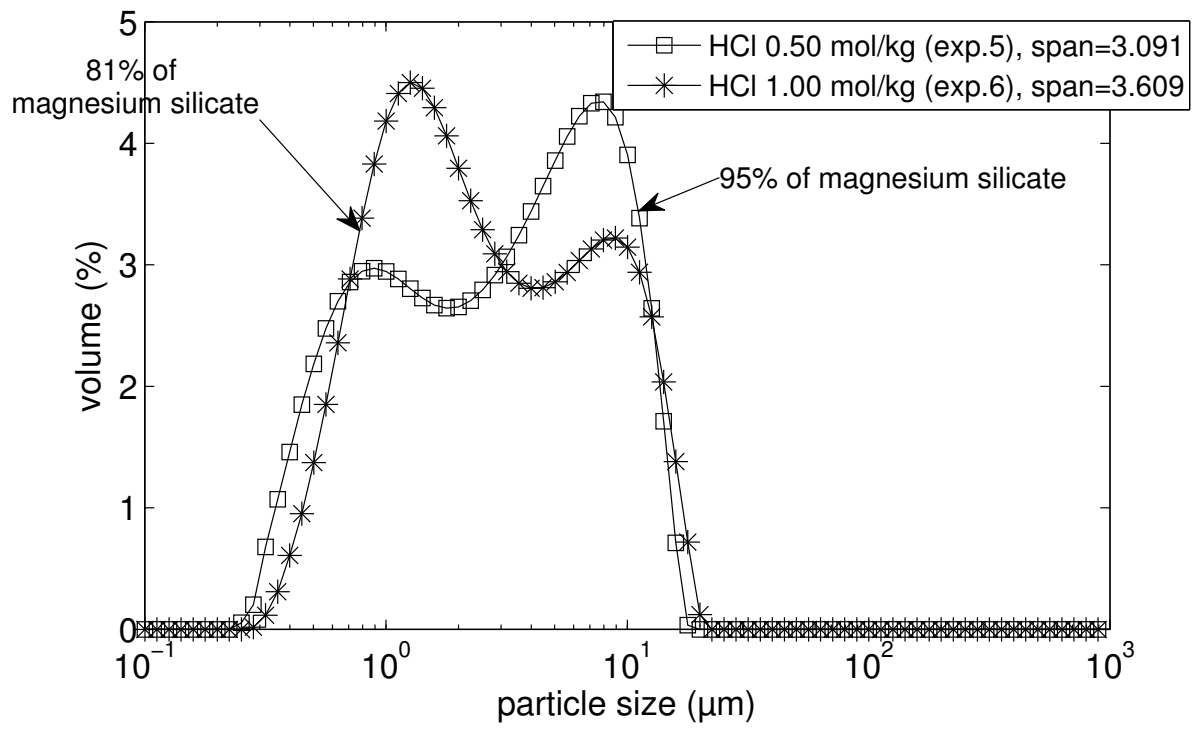

Figure 15: Particle-size distributions as a function of $\mathrm{HCl}$ molality. Parallel reactant addition with mixing system and ultrasound is used $\left(\left[\mathrm{MgCl}_{2}, 6 \mathrm{H}_{2} \mathrm{O}\right]=0.73 \mathrm{~mol} \cdot \mathrm{kg}^{-1}, \mathrm{~T}=20^{\circ} \mathrm{C}\right)$.

\subsubsection{Ultrasound during the synthesis}

At low molalities $\left(\left[\mathrm{MgCl}_{2}, 6 \mathrm{H}_{2} \mathrm{O}\right]=0.73 \mathrm{~mol} \cdot \mathrm{kg}^{-1},[\mathrm{HCl}]=0.50 \mathrm{~mol} \cdot \mathrm{kg}^{-1}\right)$, with ultrasound used during the synthesis made by parallel reactant addition with the mixing system, smaller particles are observed (Fig. 17). Particlesize distributions are very different. Particle sizes are smaller than $20 \mu \mathrm{m}$ with ultrasound as against $70 \mu \mathrm{m}$ without ultrasound in the mixing system.

The same result is observed on products made up of magnesium silicate and silica (Fig. 18).

Ultrasound would thus appear to reduce particle sizes and prevent agglomerates from forming. Therefore secondary agglomerates are formed during the drying step. The same results on size reduction have been found with the synthesis of $\mathrm{BaSO}_{4}, \mathrm{~K}_{2} \mathrm{SO}_{4}, \mathrm{TiO}_{2}$ and sucrose particles [9]. In these works, ultrasound treatment produces a decrease in particle size in comparison with the same physical or chemical process without ultrasound. 


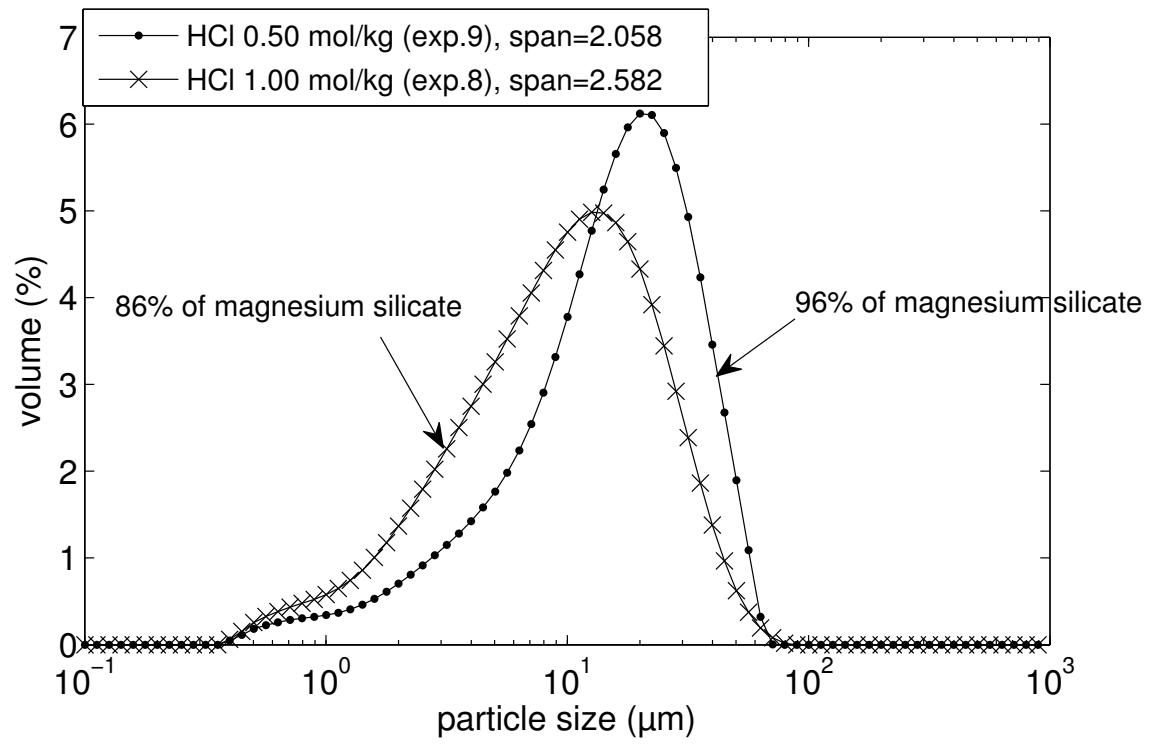

Figure 16: Particle-size distributions as a function of $\mathrm{HCl}$ molality. Parallel reactant addition with mixing system is used $\left(\left[\mathrm{MgCl}_{2}, 6 \mathrm{H}_{2} \mathrm{O}\right]=0.73 \mathrm{~mol} \cdot \mathrm{kg}^{-1}, \mathrm{~T}=20^{\circ} \mathrm{C}\right)$.

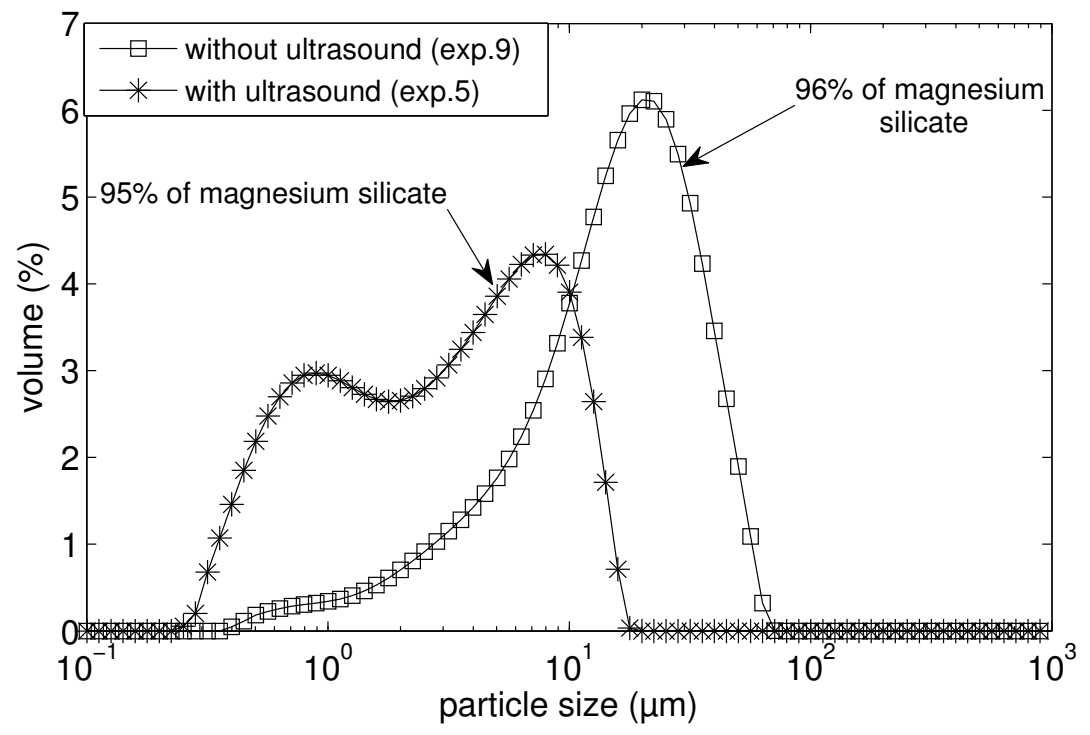

FiguRE 17: Particle-size distributions as a function of ultrasound used during the synthesis. Parallel reactant addition with mixing system is used $\left(\left[\mathrm{MgCl}_{2}, 6 \mathrm{H}_{2} \mathrm{O}\right]=0.73 \mathrm{~mol}^{\mathrm{kg}} \mathrm{kg}^{-1}\right.$, $\left.[\mathrm{HCl}]=0.50 \mathrm{~mol} \cdot \mathrm{kg}^{-1}, \mathrm{~T}=20^{\circ} \mathrm{C}\right)$. 


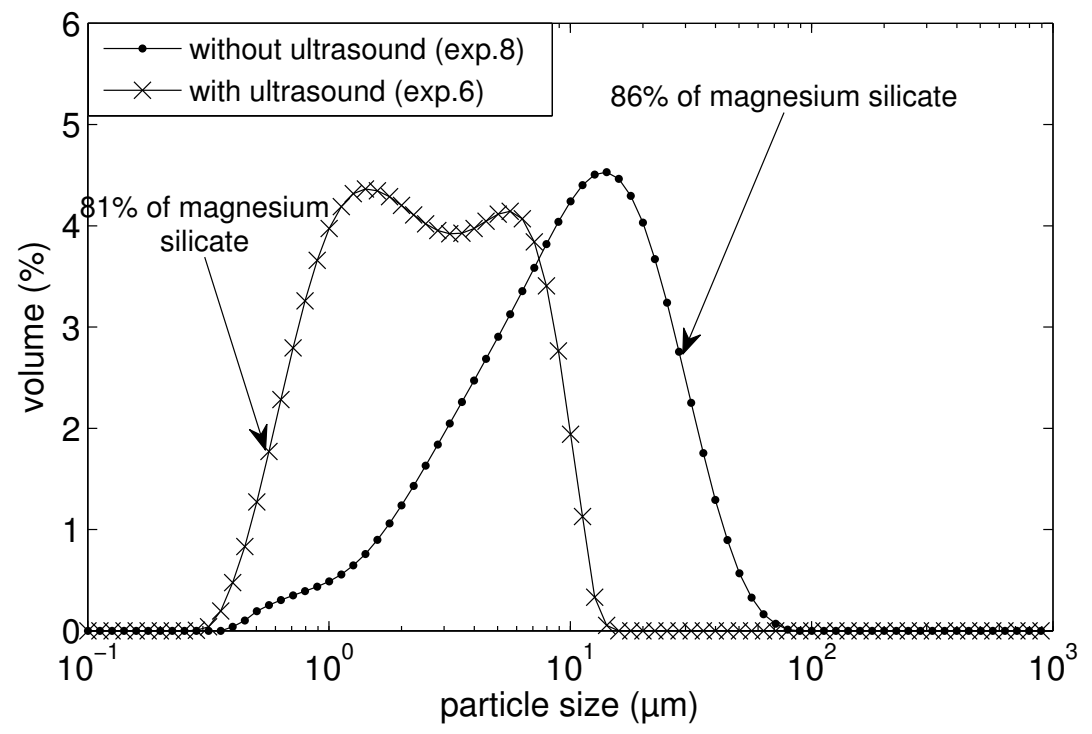

Figure 18: Particle-size distributions as a function of ultrasound used during the synthesis. Parallel reactant addition with mixing system is used $\left(\left[\mathrm{MgCl}_{2}, 6 \mathrm{H}_{2} \mathrm{O}\right]=0.73 \mathrm{~mol} \cdot \mathrm{kg}^{-1}\right.$, $\left.[\mathrm{HCl}]=1.00 \mathrm{~mol} \cdot \mathrm{kg}^{-1}, \mathrm{~T}=20^{\circ} \mathrm{C}\right)$.

\subsection{Solid structure and dispersion}

The dry solid is composed of fine particles that are strongly agglomerated (Fig. 19). The amorphous product seems to be made up of two kinds of agglomerates. Secondary agglomerates (Fig. 19a and 19b) are made up of primary agglomerates (Fig. 19c), which are made up of primary spherical particles whose size is about $200 \mathrm{~nm}$ (Fig. 19d). The drying step in the drying oven modifies the structure of the secondary agglomerates. Three other drying techniques were tested : freeze-drying, spray-drying and drying by extraction by supercritical $\mathrm{CO}_{2}$. These drying techniques reduce secondary agglomeration (Fig. 20). After drying by extraction by supercritical $\mathrm{CO}_{2}$ or by spray-drying, secondary agglomerates seem to be the smallest (Fig. 20c and 20d). Moreover, the spray-drying technique enables spherical secondary agglomerates to be obtained. After the freeze-drying step, secondary agglomerates seem to be made up of sheets (Fig. 20b), contrary to secondary agglomerates that are obtained after the three other drying techniques. The structure of these sheets is the same as the structure of the primary agglomerates of other solids : spherical primary agglomerates are observed. Their mean size is about $200 \mathrm{~nm}$.

Differences between solids are also observed on nitrogen adsorption and 


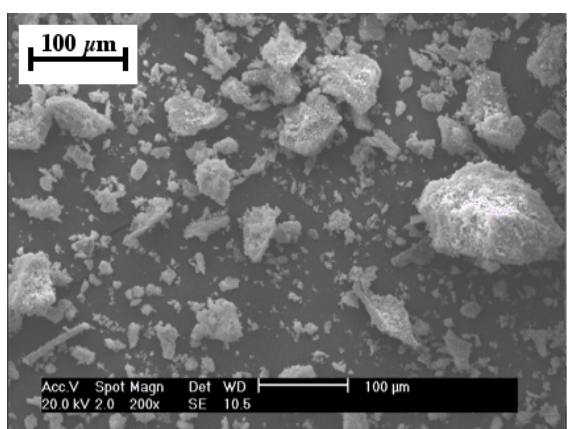

(a) $\mathrm{x} 200$

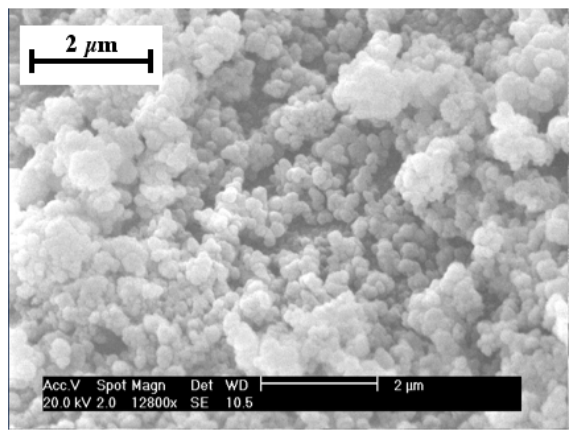

(c) $\mathrm{x} 12800$

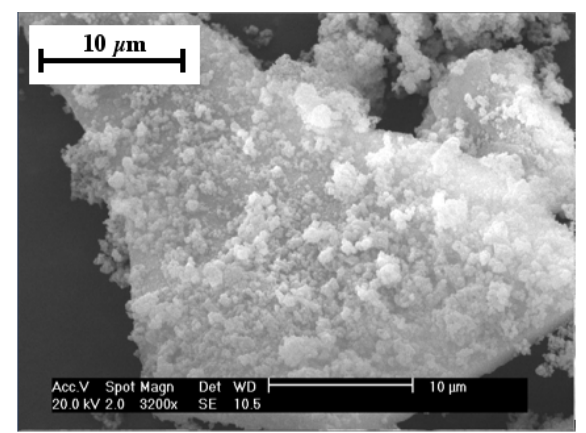

(b) $\times 3200$

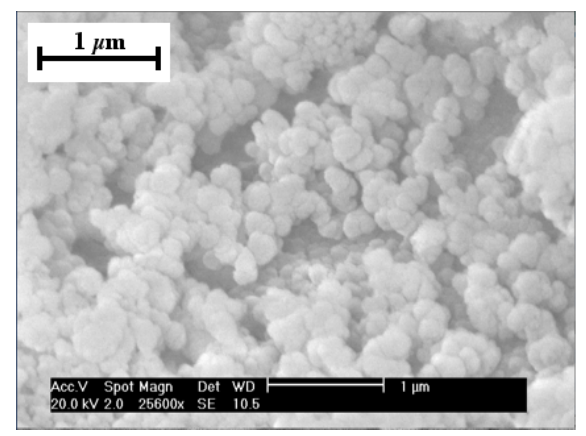

(d) $\mathrm{x} 25600$

FIGURE 19: SEM analyses of products synthesized by slow addition, $\left[\mathrm{MgCl}_{2}, 6 \mathrm{H}_{2} \mathrm{O}\right]=1.47 \mathrm{~mol} \cdot \mathrm{kg}^{-1}, \mathrm{~T}=20{ }^{\circ} \mathrm{C}$. 


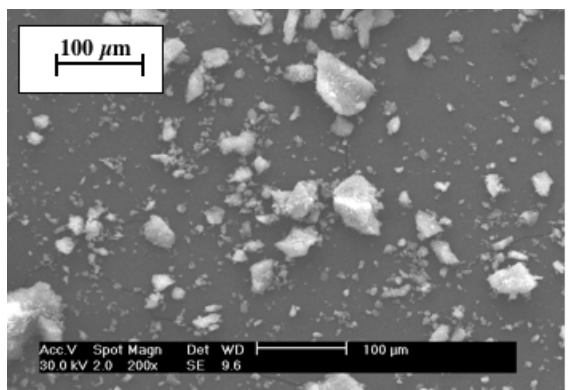

(a) drying oven

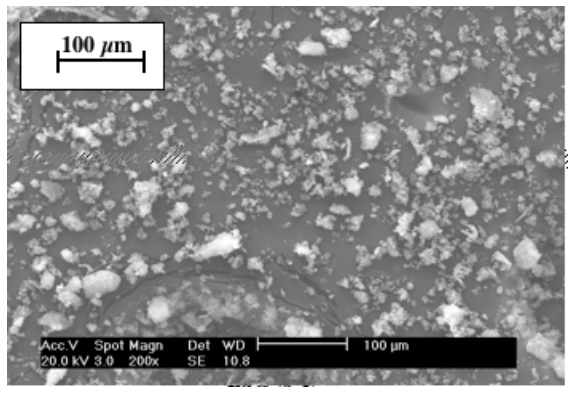

(c) extraction by supercritical fluid

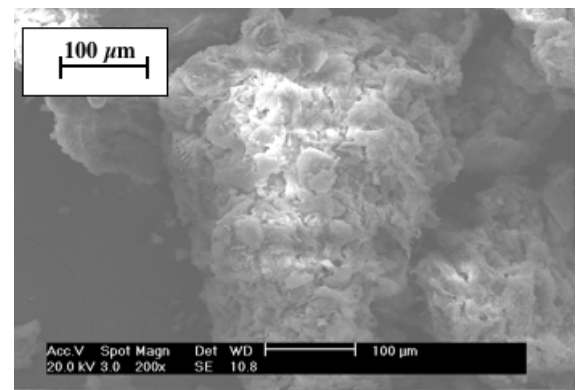

(b) freeze-drying

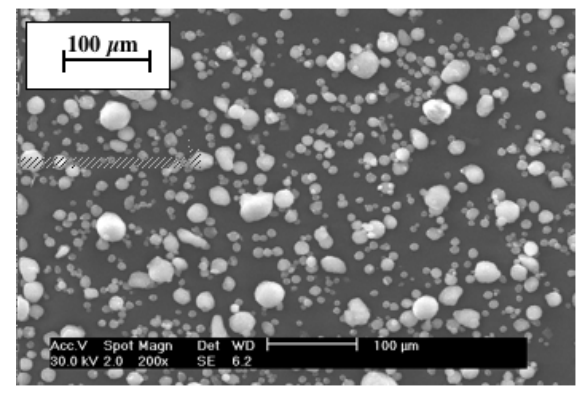

(d) spray-drying

FIGURE 20: SEM analyses of products dried by different techniques. 
desorption isotherms. During every analysis, there is a gas adsorption at very low relative pressure that shows the presence of micropores inside solids. These micropores appear to be between primary particles, inside primary agglomerates (Fig. 21). At high relative pressure $(\simeq 1)$, a difference is observed in the isotherms. There is a plateau on the desorption field of several experiments. This plateau indicates there are mesopores inside the solid. These mesopores appear to be between primary agglomerates, inside secondary agglomerates (Fig. 21b). This plateau is not observed for experiments 2,7 and 8, so there wouldn't appear to be real mesopores inside these solids. Thus the primary agglomerates seem to be spaced out. MEB analyses show secondary agglomerates may exist but they would be fragile. These agglomerates are probably formed during the drying step in the drying oven. The structure of these solids seems to be less compact, more airy.

Table 6 summarizes results obtained from nitrogen adsorption/desorption analyses and dispersion tests. $d_{50}^{s}$ represents the median diameter measured at the end of the synthesis, $d_{50}^{d}$ is the median diameter measured at the end of the dispersion test and $\Delta\left(d_{50}\right)$ is the difference $d_{50}^{d}-d_{50}^{s} . V_{\text {meso }}$ and $V_{\text {micro }}$ are mesoporous and microporous volumes, $d_{\text {meso }}$ and $d_{\text {micro }}$ are diameters of mesopores and micropores. These four properties are calculated from nitrogen adsorption/desorption analyses. Measured microporous volumes are in the same order of size as the microporous volumes that were measured by Sayan, Titiz-Sargut, Ozgul-Yucel, and Kiran [20] on synthetic magnesium silicates.

\begin{tabular}{|cccccccc|}
\hline Experiment & $\begin{array}{c}\mathrm{d}_{50}^{s} \\
(\mu \mathrm{m})\end{array}$ & $\begin{array}{c}\mathrm{d}_{50}^{d}(\mu \mathrm{m}) \\
(\mu \mathrm{m})\end{array}$ & $\begin{array}{c}\Delta\left(\mathrm{d}_{50}\right) \\
\left(\mathrm{cm}^{3} \cdot \mathrm{g}^{-1}\right)\end{array}$ & $\begin{array}{c}\mathrm{d}_{\text {meso }} \\
(\mathrm{nm})\end{array}$ & $\begin{array}{c}\mathrm{V}_{\text {micro }} \\
\left(\mathrm{cm}^{3} \cdot \mathrm{g}^{-1}\right)\end{array}$ & $\begin{array}{c}\mathrm{d}_{\text {micro }} \\
(\mathrm{nm})\end{array}$ \\
\hline \hline 1 & 20,9 & 13,9 & $-7,0$ & 0,15 & 21 & 0,12 & \\
2 & 26,0 & 13,7 & $-12,3$ & & & 0,12 & 0,46 \\
7 & 19,2 & 23 & 3,8 & & & 0,04 & 0,68 \\
26 & 15,9 & 20,7 & 4,8 & 0,34 & 33 & 0,10 & 0,64 \\
9 & 16,9 & 23,8 & 6,9 & 0,47 & 31 & 0,09 & 0,57 \\
8 & 11,2 & 24,7 & 13,5 & & & 0,08 & \\
16 & 5,9 & 50,4 & 44,5 & 0,41 & 25 & 0,12 & 0,54 \\
6 & 4,2 & 53 & 48,8 & 0,51 & 23 & 0,09 & 0,58 \\
5 & 3,2 & 79,6 & 76,4 & 0,27 & 20 & 0,03 & \\
\hline
\end{tabular}

TABLE 6: Nitrogen adsorption and dispersion properties of solids.

The assumption about the difference between solid structures is confirmed by the dispersion tests (Fig. 22). During these tests, solids from experiments 1 and 2 are rapidly dispersed in water (Fig. 22a) and the median diameter respectively reaches $13.9 \mu \mathrm{m}$ and $13.7 \mu \mathrm{m}$. These values are lower than those measured during the synthesis (Tab. 6). These solids are easy 


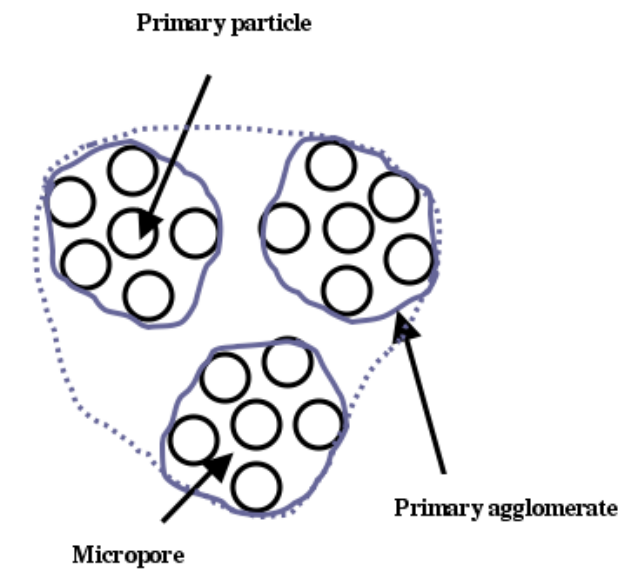

(a)

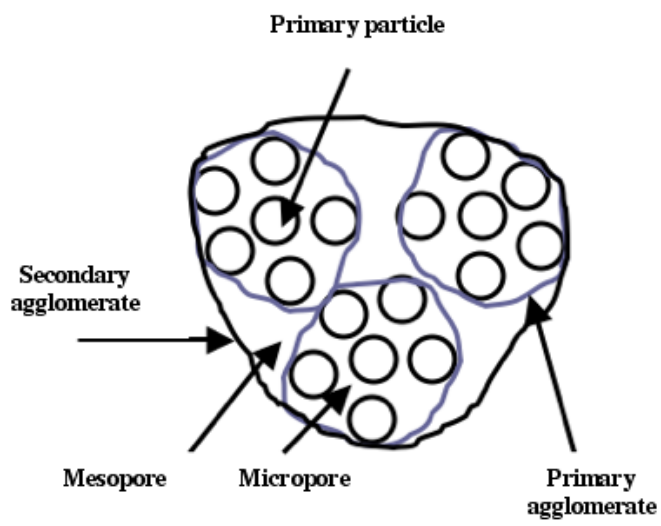

(b)

FIGURE 21: Structure of the solid (a : without mesopores; $\mathrm{b}:$ with mesopores)

to disperse, which indicates an airy structure with secondary agglomerates that break easily. The dispersion of solids obtained with the mixing system is more difficult (Fig. 22b, Fig. 22c). Final values are higher than values measured during the synthesis (Tab. 6). Products made with mixing system are difficult to disperse, which implies a more compact structure with secondary agglomerates that do not break down. Moreover the larger the mesopores are, the easier is the dispersion : solids with smaller mesopores between 20 and $25 \mathrm{~nm}$ present the most difficult dispersion in water (mean difference between 3 experiments : $\left.\Delta\left(d_{50}\right) \simeq 56.6 \pm 17.3\right)$ whereas solids with larger mesopores, between 31 and $33 \mathrm{~nm}$, present an easier dispersion (mean difference between 2 experiments $\Delta\left(d_{50}\right) \simeq 5.9 \pm 1.5$ ) (Tab. 6, Fig. 22b, Fig. 22c). 
This last observation confirms the assumption that the airier the structure, without mesopores or with large mesopores, the easier the dispersion in water. 


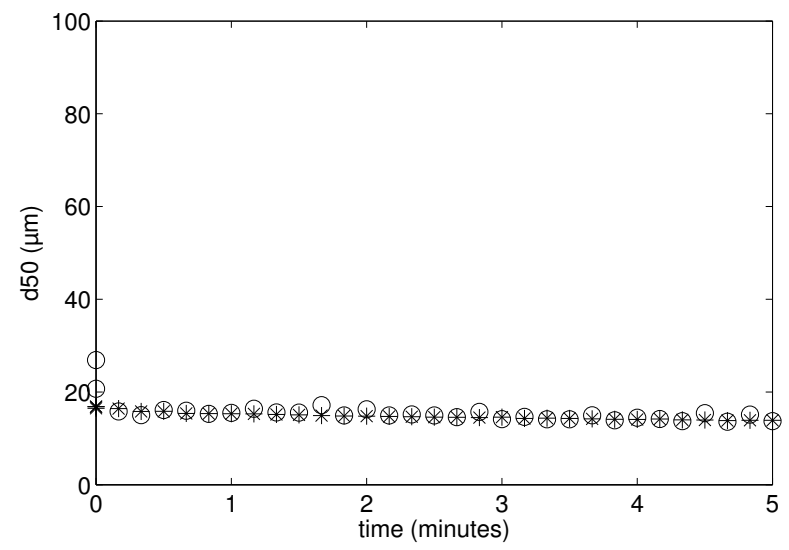

(a) * magnesium silicate, slow addition (exp.1); ○ magnesium silicate, fast addition (exp.2)

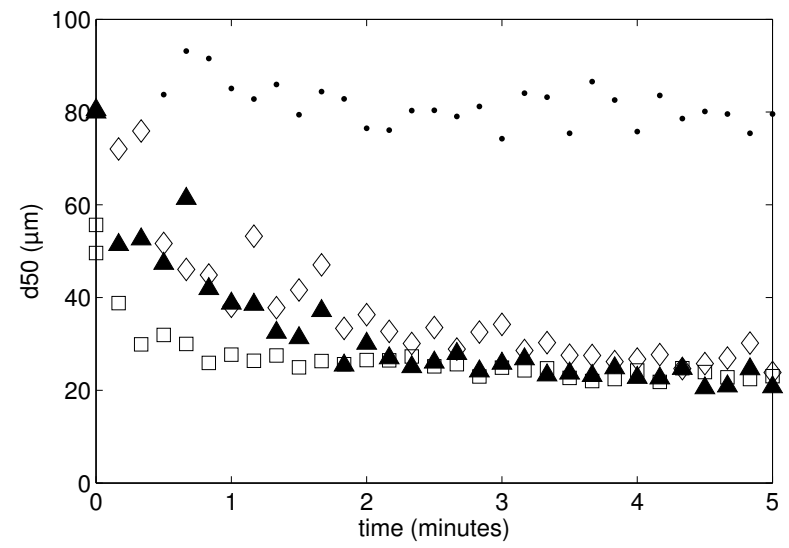

(b) $\Delta$ magnesium silicate, MS+US (exp.26); $\diamond$ magnesium silicate, MS (exp.9); $\square$ magnesium silicate, MS+US (exp.7); • magnesium silicate, MS+US (exp.5)

Figure 22 


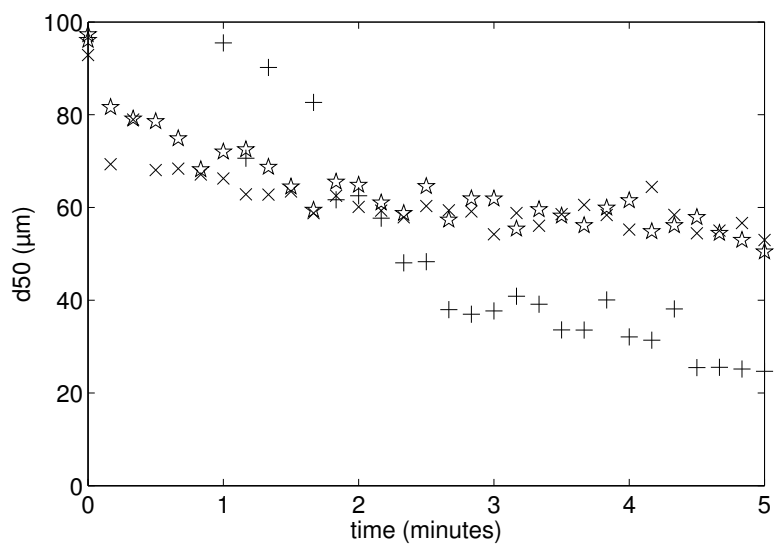

(c) $\times$ magnesium silicate+silica, MS+US (exp.6); + magnesium silicate+silica, MS (exp.8); magnesium silicate+silica, $\mathrm{MS}+\mathrm{US}+50^{\circ} \mathrm{C}(\exp .16)$

FIGURE 22: Solid dispersion in water as a function of process parameters $(\mathrm{MS}=$ mixing system ; US=ultrasound).

(a) : addition mode influence on solids made up of magnesium silicate ( $w_{\text {magnesiumsilicate }} \geq$ $96 \%)$

(b) : US and initial reactant concentration influence on solids made up of magnesium silicate $\left(w_{\text {magnesiumsilicate }} \geq 96 \%\right)$;

(c) : US and temperature influence on solids made up of magnesium silicate and silica $\left(w_{\text {magnesiumsilicate }} \geq 81 \%\right)$. 


\section{Conclusions}

The process parameters studied (reactant-addition mode and order, reactant molalities and ultrasound) do not appear to influence the crystallinity rate of the synthesized product,which is amorphous in all cases.

It is also highly agglomerated, whichever process parameters are used, even if the structure of the agglomerates varies according to the parameters. The reactant-addition mode appears to have the most important effect on solid structure. Solids that stem from experiments made with slow or fast addition seem to have a more airy structure than solids made with the mixing system. Consequently, these solids easily disperse in water. Correlations between the solid structure and its dispersion behaviour have been established. These are novel aspects of the magnesium silicate study and make it possible to understand solid dispersion behaviour as a function of process parameters.

On the other hand, some parameters seem to reduce agglomerates sizes. In order to synthesize the smaller agglomerates and particles, reactant addition by the mixing system with ultrasound used during the synthesis appears to be the most appropriate method. Median agglomerate sizes that are obtained under these conditions are about $3 \mu \mathrm{m}$. This is larger than the desired size but is the size of the agglomerates size and not the primary particles. SEM analysis indicates that the primary particle size is about $200 \mathrm{~nm}$. Therefore, solids that stem from experiments made with these parameters have a more compact structure and thus are more difficult to disperse in water.

Drying techniques also influence secondary agglomeration. Spray-drying and drying by extraction by supercritical $\mathrm{CO}_{2}$ enable the secondary agglomerates size to be reduced.

Initial reactant molalities influence the agglomeration phenomenon by means of the nucleation rate. High initial molalities would enable more particles to be synthesized and thus increase the agglomeration phenomenon.

Therefore, $\mathrm{HCl}$ molality influences solid purity. If the synthesis is made with an excess of $\mathrm{HCl}$, amorphous silica co-precipitates with magnesium silicate. This problem was not found during recent studies of magnesium silicate precipitation. A solution has been found to this problem and now process parameters for obtaining magnesium silicate without silica are known. In order to avoid silica precipitation, hydrochloric acid must not be used in excess in initial reactant solutions.

Another novel aspect of this work is the determination of the magnesium silicate equilibrium constant by speciation calculations. From equilibrium constant determination, the magnesium silicate supersaturation ratio will 
be calculated during the synthesis and as a function of process parameters.

Other works could be done in order to further study synthetic magnesium silicate. The product must be easily disaggregated in the polymer matrix in order to obtain nano-sized primary particles that are well-dispersed in the polymer. Solid treatment has been envisaged in order to reduce agglomeration phenomena during the drying step, or at least make secondary agglomerates more fragile. Thus,solid disagglomeration would be easier and its dispersion would be better. Experiments are in progress and a friability test is being developed in order to characterize treatment effects on solid agglomeration. 


\section{Acknowledgements}

The authors acknowledge the Agence Nationale de la Recherche for the financial support of the ANR-09-MAPR-0017 project. The authors also thank Ms C. Rolland for microscopy analyses, Ms S. Patry for X-Ray diffraction analyses, Ms M.-A. Piquemal, Ms H. Leroy and Ms J. Ferret of Imerys Talc for XRF analyses. 
[1] F. Ciesielczyk, A. Krysztafkiewicz, K. Bula, T. Jesionowski, Evaluation of synthetic magnesium silicate as a new polymer filler, Composite Interfaces 17 (2010) 481-494.

[2] Tufar, Talc, 2000.

[3] F. Martin, Le talc : un minéral idéal ?, Habilitation à Diriger des Recherches, Université Toulouse III, Paul Sabatier, 1999.

[4] F. Martin, J. Ferret, C. Lèbre, S. Petit, O. Grauby, J.-P. Bonino, D. Arseguel, A. Decarreau, Procédé de préparation d'une composition de talc synthétique à partir d'une composition de kérolites, Brevet d'invention français FR2903682 - A1 - 2006, 2006.

[5] C. Lèbre, Elaboration et caractérisation de talcs synthétiques pour l'amélioration des propriétés physiques des matériaux composites industriels, Ph.D. thesis, Thèse de l'Université de Toulouse III, 2007.

[6] F. Ciesielczyk, A. Krysztafkiewicz, T. Jesionowski, Influence of surface modification on morphology and physicochemical parameters of synthetic magnesium silicate., Physicochemical Problems of Mineral Processing 39 (2005) 155-164.

[7] F. Ciesielczyk, A. Krysztafkiewicz, T. Jesionowski, Physicochemical studies on precipitated magnesium silicates, Journal of Materials Science 42 (2007) 3831-3840.

[8] A. Mersmann, Crystallization and precipitation, Chemical Engineering and Processing 38 (1999) 345-353.

[9] J. Dodds, F. Espitalier, O. Louisnard, R. Grossier, R. David, M. Hassoun, F. Baillon, C. Gatumel, N. Lyczko, The effect of ultrasound on crystallisation-precipitation processes : Some examples and a new segregation model, Particle \& Particle Systems Characterization 24 (2007) $18-28$.

[10] J. Fages, J.J. Letourneau, M. Sauceau, E. Rodier, Élaboration de solides divisés par fluides supercritiques, Techniques de l'Ingénieur RE 26 (2005) 1-12.

[11] E. Custodero, L. Simonot, J.-C. Tardivat, Reinforcing aluminum-based filler and rubber composition comprising such a filter, 2003. 
[12] S. R. Charlton, D. L. Parkhurst, Modules based on the geochemical model PHREEQC for use in scripting and programming languages, Computers \& Geosciences 37 (2011) 1653-1663.

[13] I. Gunnarsson, S. Arnorsson, Amorphous silica solubility and the thermodynamic properties of $\mathrm{H} 4 \mathrm{SiO} 4$ degrees in the range of 0 degrees to 350 degrees C at P-sat, Geochimica et Cosmochimica Acta 64 (2000) $2295-2307$.

[14] M. Azaroual, C. Fouillac, J. Matray, Solubility of silica polymorphs in electrolyte solutions .1. Activity coefficient of aqueous silica from 25 degrees to 250 degrees C, Pitzer's parameterisation, Chemical Geology 140 (1997) 155-165.

[15] J. Baldyga, M. Jasinka, K. Jodko, P. Petelski, Precipitation of amorphous colloidal silica from aqueous solutions, (2011).

[16] J. Sefcik, A. McCormick, Thermochemistry of aqueous silicate solution precursors to ceramics, AICHE Journal 43 (1997) 2773-2784.

[17] R. Garrels, J. Christ, Solution, minerals, and equilibria, 1965.

[18] R. Zauner, A. Jones, Mixing effects on product particle characteristics from semi-batch crystal precipitation, Chemical Engineering Research \& Design 78 (2000) 894-902.

[19] J. Baldyga, L. Makowski, W. Orciuch, Double-feed semibatch precipitation - effects of mixing, Chemical Engineering Research \& Design 85 (2007) 745-752.

[20] P. Sayan, S. Titiz-Sargut, S. Ozgul-Yucel, B. Kiran, Physical and Adsorptive Characterization of Precipitated Magnesium Silicate from Rice Hull Ash Silica, Chemical Engineering \& Technology 34 (2011) 14971506. 